\title{
CHAPTER 64
}

\section{A PERFORATED MOBILE BREAKWATER FOR FIXED AND FLOATING APPLICATION}

\author{
Wilbur Marks \\ Executive Vice-President, Oceanics, Inc. \\ Technical Industrial Park, Plainvıew, N. Y.
}

\begin{abstract}
ABST RACT
A mobile breakwater concept based upon a perforated front wall and solid back wall is presented. The principles of energy dissipation by the system is discussed as well as the potential role of such a device within the framework of practical application. Model test results, comparing the perforated breakwater's response to waves with that of a caisson-type breakwater, are discussed. It is shown that the perforated breakwater experiences less force on the structure when it is fixed to the bottom and less force on the mooring lines when afloat than the caisson-type. However, the perforated breakwater is not more effective in reducing waves, for the conditions tested. Visual observations show that scouring is prevalent when the calsson-type is fixed to the bottom; there is no evidence of scouring with the perforated breakwater. Recommendations are made for future work.
\end{abstract}

\section{INTRODUCTION}

Amphibous operations often require the use of man-made means of reducing the hazards due to waves so that personnel and equipment may be put ashore quickly, safely, and in good condition. To this end It may be desirable, even necessary, to provide a breakwater system that can protect against waves and that will also function as a pier and create a harbor. However, for the purposes of this program, the proposed design concept is only evaluated from the point of vew of efficient wave damping on the shoreward side. Inherent in the design principles is direct adaptation to the pier and harbor aspects but these applications are not considered here.

Although, during the last 25 years, many different kinds of breakwaters have been proposed ( $\mathrm{O}^{2}$ Brien, Kichenreuther, and Jones, 1961 and Bulson, 1964) none has achleved a universal acceptance and the reasons for this become apparent upon consideration of the severe requirements imposed on such a system. These requirements, as abstracted from O'Brien, Kichenreuther, and Jones (1961), constitute the framework within which the proposed breakwater must eventually be evaluated.

1. The basic breakwater unit shall be prefabricated of uncritical material and be modular in desıgn. 
2. The unit shall be capable of being towed to its installation site at a minimum speed of 5 knots in all reasonable sea conditions and with a minumum number of towboats.

3. The breakwater shall be suitable for installation on different types of sea floors.

4. Installation shall be possible in all reasonable sea states and shall not exceed 2 days.

5. Once in place, the breakwater shall perform by reducing a maximum design wave 15 feet high and 444 feet long in 40 feet of water (exclusive of a 12-foot tidal range), to 4 feet high inshore of the breakwater.

6. The breakwater shall withstand the maximum design storm (near hurricane proportions).

7. Removal of the breakwater and storage or reinstallation at a different site shall be feasible and suitable for accomplishment by mulitary personnel.

8. To justify the expected cost, the breakwater must be able to serve from six months to a year at an amphibious landing site and for several years at an advance base with only routine maintenance by miltary personnel.

Judging from the literature, it is safe to say that virtually all proposed solutions to this problem have been found wanting in one or more of these fundamental criteria. Of course, the requirements are not weighted equally. Items 5 and 6 must obviously be satisfied furst and then perhaps item 2. The remaining items are certainly important, but unless the operational characteristics are certified satisfactory, the system has little value.

The breakwaters used in World War II were usually fixed to the bottom, after being floated into place. They invarlably failed in high wave conditions, because scouring undermined the foundations and, once vulnerable to wave action, the units were often overturned or at least knocked askew. To be sure, there was virtually no wave action on the shoreward side of the system, but the potential energy in the wave unleashed such enormous forces on the structure that it was often rendered useless before its task was accomplished.

From the point of view of performance, and this is the chief criterion in the first instant, it is necessary to develop a breakwater system that a prior can withstand the forces that tend to disrupt its orientation. This applies whether the breakwater is fixed or floating; 
but in the floating condition, it is also necessary to achieve a given reduction in wave height. There is no clear preference for fixed or floating breakwaters; each has certain engineering and logistic virtues (and deficiencies) which vary with the particular concept being advocated.

The purpose of the work reported here is to evaluate the merits of a perforated breakwater as a system for damping waves. Since there are no portable breakwaters in existence, the measure of performance has been specified with respect to the plane-wall or caisson-type breakwater which is believed to be the most reliable concept presently available. What must be demonstrated is that the perforated breakwater has suitable wave-damping characteristics in the floating (1. e. moored) condition and/or experiences significantly less force than the caisson, when fixed to the bottom.

This report describes a serles of experıments armed at comparing the behavior of the perforated breakwater and the calsson-type with regard to total force on the structure, when it is fixed to the bottom, and with regard to wave-damping and force on the mooring lines when it is floating.

\section{GENERAL DISCUSSION OF PROPOSED SYSTEM}

The basic purpose of any breakwater system is to present an obstacle to the oncoming waves that will cause the wave height (hence energy) to be substantially reduced on the shoreward side, without compromising the functional efficiency of the breakwater system during the required tıme of operation. The perforated breakwater has been specifically designed for such a mission. The origunal concept of a perforated breakwater was developed by Jarlan (1965) at the National Research Council in Canada. This study is concerned with the application of that breakwater as a mobile system and for possible operation in the floating moored condition or fixed to the bottom.

The dynamic processes that result from the uncidence of waves on the perforated breakwater can best be visualızed by consıdering Figure 1 . As the wave impinges on the porous front wall, part of its energy is reflected and the remainder passes through the perforations. The potential energy in the wave is converted to kinetic energy in the form of a jet, upon passage through the perforation, which then tends to be partially dissipated by viscosity in the channel and partially by turbulence in the fluid chamber behind the perforated wall. As the water in the flutd chamber flows back out of the holes, it encounters the next oncoming wave and partial energy destruction is accomplished even before that wave reaches the breakwater. If the walls were not perforated (e.g. a caisson), total reflection would occur on the face of the wall with resultant high impact forces and scouring on the base, if it is fixed to the bottom. If the breakwater were floating and anchored, part of the incident wave force would 
be transmitted to the mooring cables and part would be directed to os cillating the breakwater thus inducing it to make waves on the shoreward side. In the case of the perforated breakwater, that part of the incident wave energy which is dissipated internally in the form of heat and eddies is not available for such deleterious activity. Hence, it is expected that less force would be felt in the mooring lines, and/or that smaller waves would be produced shoreward of the breakwater.

The efficiency of energy dissipation, in the breakwater principle proposed here, depends on the geometry of the system which in turn is determined by the nature of the design wave conditions. From the laws of fluid motion in the chamber, the following design criteria are obtained:

1) Ratio of chamber width to wavelength.

2) Ratio of wall thickness (channel length)to hole diameter.

3) Ratio of perforated to unperforated areas (solidity ratio).

The theoretical development leading to the establishment of the above criteria, for partıcular wave inputs, was presented by Jarlan (1965) and Jarlan and Marks (1965). Consider, for example, a "design sea state" for which an appropriate wave spectrum in shallow water is specified. The frequency of maximum energy in that spectrum might be the design criterion that will determine the chamber width, channel length, hole diameter, and solidity ratio. A breakwater designed on these geometrical specifications will have its greatest damping effect on waves at the design wavelength (1. e. frequency). At other wavelengths, the effect will be less, but those wave components have less energy. However, the diminution of effectiveness about the design wavelength is not unform; the perforated breakwater is more effective for shorter wavelengths than for longer ones.

It is now appropriate to consider the preliminary design of a unit breakwater based on the theory and conforming to the requirements listed in the Introduction. Figure 2 shows such a unit where the walls are 3 feet thick and the chamber width is about 34 feet totalling 40 feet overall from front to back wall. For a minimum design depth of 40 feet, maximum wave height of 15 feet, and tidal range of 12 feet, the breakwater height will be about 60 feet, if fixed to the bottom and 50 feet if floating. An arbitrary modular length for the unit is chosen to be 240 feet.

If the front wall of the unit breakwater is made of sandwich construction comprising 3/8-inch steel sheets with 3-foot long, 3-foot diameter cylinders, of $1 / 4$ inch steel between them and styrofoam-1ike material is packed in all the empty space, then the buoyancy requirement can be met for the floating case. The styrofoam provides flotation without the necessity of watertight welds on the cylindrical channels 
which also act as stiffeners. If, in addition, a one foot, or so, space at the bottom is made watertight, this reserve buoyancy could be used to change the water line for different depth and tide conditions.

The back wall is also of sandwich construction with stiffeners and styrofoam between the steel sheets. Across the bottom is simply a 3/8-inch steel sheet with perforations to munimize heave and hence wave generation. Bracing members between the front and back walls would be optimally spaced to provide maximum rigidity for the unit. Additional braces fixed to the bottom plate will protect against the large vertical forces that may occur. The mooring arrangement and strength thereof must be carefully designed not only for holding the breakwater in place but to minimize motion of the breakwater that could produce undesırable generation of waves.

The basic breakwater unit, when combined with similar units to form a complete system must meet the eight requirements listed in the Introduction. The initial study being reported here only treats some of those aspects relating to the performance of the system during actual operation. However, for the sake of completeness, the following dis cussion will touch briefly on all the requirements listed in the Introduction and in the same order.

1. The basic unit, as sketched in Figure 2, comprises a front wall, back wall, bottom and bracing. The suggested materials are steel and styrofoam. The construction is quite stralghtforward but must contain provision for fastening of the girders and bottom plate. In addition, means must be provided for flooding the alr chambers at the bottom of the front and back walls and for evacuating them as required. A survey on worldwide avallability of materials and sites for construction is important for long-range operational planning. However, it is likely that sections could be prefabricated and shipped to convenient places for assembly.

2. It is proposed to minimize the number of towboats by trans porting the unit breakwaters in a collapsed state. That is, with all the girder bracing removed and the hinged bottom raised, the front and back walls will occupy a minimum of space for towing purposes (Figure 3). Allowing 8 feet for each complete unit and a 20-foot space as shown in Figure 4, five units would occupy a space 240 feet long by 60 feet wide by 50 feet deep. If an artificial bow were installed on one end of the set of unit breakwaters, the entire "package"would be suitable for tow ing. The artuficial bow is not only useful for minimizing towing resistance but could be used to accommodate all the personnel, equipment and girder bracing for installation. The arrangement 
of the elements of the breakwater in the towing packages will be discussed under Item 4. Suffice to say here that back walls should be located on the outside of the package to eliminate the turbulence due to the holes. In addition, the towing package could be fitted with a small crane to assist in rigging.

It is necessary to determine the optimum shape of the bow and optimum draft for minimum towing resistance. An analytical study should be made of a towing design with a minimum 5-knot speed capability. After the operational requirements of the breakwater are successfully demonstrated, it would be necessary to carry out model tests to evaluate the tow ing aspect of the problem.

3. In principle, the breakwater fixed rigidly to the bottom would provide maximum wave reduction. But there is the problem of large destructive forces on such a rigid system, and of scouring, that has resulted in severely damaged breakwaters in the past. These problems are lessened when the breakwater is floating. Also, when the seas are too rough for any activity, it is desirable for the breakwater to be less effective and hence transmit less force to the mooring system. However, by the very nature of the perforated breakwater design, the wave forces are partially dissipated internally, so that the large forces of short duration that are anathema to the structure and to its mooring system are minimized, as is the scouring effect of the orbital motion at the base of the front wall, when it is positioned on the bottom.

In any case, a thorough evaluation should encompass both moored-floating and bottom-mounted systems. Strain gages in the cables can measure the forces experienced in different states of sea and such information will aid in the design of optimum arrangement of the mooring system. The same data on expected forces coupled with information on the yield strength of different types of bottom will permit specification of particular anchoring mechanisms associated with each type of bottom. For the bottom-mounted case, total force measurement is a good index for comparison of breakwater concepts as well as a measure of the overturning moment.

4. The time required to install a breakwater system cannot even be estimated before a complete engineering design is developed. In fact, the necessity for efficient and speedy installation will certainly influence the design. However, it will be passible to speculate on an optimum procedure for installation. This will be done for the moored system, but the general method 
applies to the bottom-mounted breakwater, as well.

As mentioned in Item 2, the breakwater system wo uld be delivered in the collapsed state, the basic requirement being that the outside walls of the towed package be "back"walls. If the elements are arranged as show $\mathrm{n}$ in Figure 4, then the beam would be 60 feet. The 20 -foot gap in the middle provides the required spacing between appropriately paired front and back walls. If, in addition, the units are yoked at top and bottom as shown, the entire towed system will remain rigid and parred units will always be properly spaced.

Upon installation, $B_{1}$ is closest to the beach. When $F_{1}$ is released from all the yokes except $y_{1}$, and $B_{1}$ is released from $\mathrm{y}_{6}$ and $\mathrm{y}_{7}$, the breakw ater unit $\mathrm{F}_{1}-\mathrm{B}_{1}$ is ready for installation. The first step is to anchor $F_{1}-B_{1}^{1}$ at the aft end. Next, the package is tow ed forward about 70 feet leaving that much of $\mathrm{F}_{1}-\mathrm{B}$ exposed at the rear as $1 \mathrm{t}$ slides through the yokes. A 60 -foot section of bottom is low ered into place from its folded position against $B_{1}$. Cross bracings are placed with the assistance of the crane mounted on yokes $y_{5}$ and $y^{\prime}{ }_{5}$. Exposure of another 60-foot section follows and so on until the unit is free, secured, and fully anchored. In the anchored position, the unit is either raised or low ered (through activation of the buoyancy chambers) and the anchor cables are given final adjustment.

At this point, the rest of the units are all facing the wrong way and the system must be turned around $180^{\circ}$ and lined up with the installed unit $\left(F_{1}-B_{1}\right)$. Next, $F_{2}-B_{2}$ is installed in exactly the same way as $\frac{1}{F}-B_{1}$. The procedure is repeated till only the last unit, $F_{5} B_{5}$ remains. $F_{5}-B_{5}$ is installed in much the same fashion, except that no forward towing is involved. Instead yokes $\mathrm{y}_{5}$ and $\mathrm{y}^{\mathbf{t}}{ }_{5}$ that hold the crane and $\mathrm{y}_{7}$ are moved slowly tow ard the bow to facilitate handling of the cross bracing. Upon completion of this last installment, unit $\mathrm{F}_{5}-\mathrm{B}_{5}$ remains fixed to the bow and supports the crane. The buoyancy condition on $\mathrm{F}_{5}-\mathrm{B}_{5}$ to maintain design draft will be different from that on the other four units.

5.6. It goes without saying that unless the breakwater performs as required, compliance with the rest of the specifications is academic. The first steps tow ard evaluating the requirements posed by these two items have been taken and are reported in detall in later sections. 
7. Removal of the breakwater is essentially the reverse process of installation (Item 4). Presumably time is not a factor so the different parts may be cleaned and replaced, if necessary, prior to storage. The form in which the breakwater was delivered is the form in which it is stored. Once the breakwater is repackaged, it is immediately available for transport to another site. The apparent simplicity of installation and removal makes this system suitable for handling by military personnel. In addition, if there is no requirement for further use, after an operation, there is no reason why the entire system cannot be "mothballed" much like ships not intended for immediate use.

8. Because the breakwater is primarily of steel construction and because of its inherent potential for wave damping, it is not expected to suffer great damage in heavy seas. Indeed, a presently existing concrete version (Figure 6) has lasted three years without maintenance. It will undoubtedly be necessary to make periodic checks of moorings (or seabed) and of cross-bracing and some replacement can be expected, but this would probably be of a routine nature.

\section{MODEL TANK EXPERIMENTS}

A number of model experiments were devised for the purpose of providing a first-order evaluation of the perforated breakwater. Since the basis for evaluation is comparison of performance between a perforated and plane-wall breakwater, it was possible to vary a rather large number of experimental parameters without the sophistication that would have been required for a precise quantitative study.

The experiments can be thought of as comprising three parts: the breakwater unit fixed to the bottom, the floating breakwater unit, and the breakwater system. The first two sets of experiments were two-dimensional in nature and were carried out in the ship model tow ing tank $\left(100^{1} \times 10^{1} \times 5^{1}\right.$ deep) at Webb Institute of Naval Architecture. The three-dimensional tests were aimed at achieving a qualitative insight into performance of the breakwater as a system comprising several units; these tests were carried out at the Coastal Engineering Research Center (CERC) in one of their outdoor tanks $\left(75^{t} \times 40^{1} \times 2^{t}\right.$ deep).

For the two-dimensional tests, the Webb tank required basic modification that would permit simulation of a sloping beach and would provide anchor points to a rigid boundary for the force transmitting bar that $w$ as to be used in measurement of impact on the breakwater. After due consideration of all the constraints, it was decided to install a flume in the tank. 
The flume was designed and constructed so that a beach with slope of 1:8 extended from the wavemaker to a shallow water level one foot below the surface. The entire flume is 24 feet long and 4 feet wide with enclosed sides. Thus, at a scale of $1: 45$, the breakwater models are mounted in about 45 feet of water. The choice of scale, model size, and flume size were dictated by the geometry of the tank, the capabilities of the wavemaker, and the budget for this program. While it would have been preferable to use a larger scale (say 1:30), to demonstrate the effectiveness of the perforation, it would then not have been possible to model the design wave and this was considered to be a prime requirement. Figure 7 shows a sketch of the Oceanics flume in the Webb tank.

From the theory of the perforated breakwater, four models of different geometry were selected as being likely to demonstrate significant differences in behavior, when compared with a "solid-wall" breakwater. In addition, a breakwater with a front-wall slope of about $30^{\circ}$ was also studied. In all, seven models were tested; their characteristics are shown in Table I.

Table I. Geometrical Characteristics of Breakwater Models

$\begin{array}{lll}\text { Diameter of } & \text { Solidity (Ratio } & \text { Distance from } \\ \text { Holes and Front } & \text { of Perforated to } & \text { Front to Back } \\ \text { Wall Thickness (in) } & \text { Unperforated Areas) } & \text { Wall (in) }\end{array}$

\begin{tabular}{llcc}
\hline I & 1.16 & 0.3 & 11.6 \\
I I & 1.16 & 0.4 & 11.6 \\
I I I & 0.8 & 0.3 & 8.0 \\
IV & 0.8 & 0.4 & 8.0 \\
V & Solid front wall placed over front wall of Model I I \\
VI & Same characteristics as Model I but front wall sloped at $30^{\circ}$ \\
VI I & Solid front wall placed over front wall of Model V I.
\end{tabular}

The basic alm of these experiments was to examine the perforated breakwater as two distinctly different systems, one fixed to the bottom and the other floating and moored to the bottom. For this initial study, the necessary and sufficient condition on the fixed perforated breakwater is that it experience wave forces substantially less than those on a solid-wall breakwater. For the floating case, the same condition applies but, in addition, it is necessary to achieve a significant reduction of wave height and, in particular, to demonstrate that a 15-foot, 13-second deep-water wave, w1ll be no more than 4-feet high shoreward of the breakwater. With these conditions as the basis for the experiments, it is obvious that examination of the differen $t$ configur ations listed in Table $I$, as fixed breakwaters, would reveal the best geometrical combination for minimum force. If it is then assumed that 
the best fixed breakwater would also experience the least force on the mooring lines when floating, it becomes unnecessary to test all the perforated breakwaters in the floating condition. This was, in fact, the procedure that was followed.

The breakwater models were mounted so that the back wall was rigidly fixed to a force transmitting bar that extended across the flume (Figure 8). The front wall was fastened to the back wall by 6 rods and both walls were free of the bottom and sides (by very small clearances) and extended above the design height so that all of the force on the structure would be communicated to the bar without loss. The force transmitting bar passed through the steel side walls of the flume and was fixed rigidly at both ends to the force-measuring strain-gage systems. The strain gages were mounted rigidly to the steel side walls. Thus, the deflection of the bar relative to the rigid steel sidewalls is a measure of the force exerted on the breakwater by the waves.

Each of the two sets of strain gages comprised a vertical and horizontal unit to sense those force components. The output of the strain gages appeared as traces on a Sanborn chart recorder that described the horizontal force exerted on the structure in the downstream (with the waves) and upstream (toward the waves) directions and the vertical force in the up and down directions. In addition, the waves that resulted from the incident and reflected wave forms were measured in front of the breakwater.

Before the breakwater was installed, a series of waves was generated and recorded as they traveled the length of the flume into shallow water. A set of these waves, comprising a wide range of heights and periods, was selected as the program of wave inputs. Table II shows the incident waves used for each breakwater. More than one wave height was used for each period so that linearity of response might be studied. It was, however, recognized that shallow water waves impacting on an obstacle would be highly unlikely to induce a linear response.

Table II. Program of Wave Inputs

\begin{tabular}{cllll} 
Period (sec.) & \multicolumn{4}{l}{ Height (inches) } \\
\hline 0.85 & 1.67 & 3.33 & 6.33 & \\
0.99 & 2.33 & 3.83 & & \\
1.21 & 2.85 & 5.66 & 7.00 & \\
1.40 & 2.33 & 3.66 & 5.33 & \\
1.53 & 2.50 & 3.73 & 6.33 & \\
1.61 & 2.16 & 4.16 & 5.83 & 6.83 \\
1.79 & 1.33 & 2.93 & 3.90 & 6.95 \\
1.93 & 1.66 & 2.83 & 3.83 & 6.66
\end{tabular}


In the case of the floating breakwater, the "best" of the fixed perforated breakwaters was tested against a plane-wall unit. In both cases, the waves listed in Table II were the input to the moored system shown in Figure 9. Strain gages were installed in all four mooring lines and a pair of linear accelerometers (horizontal and vertıcal) replaced the force bar on the back wall. In addition, waves were measured behind the breakwater as well as in front. Each of the lines in the fourpoint mooring was arbitrarly attached to the breakwater at the water line and then extended to the floor of the flume at a relatively large dis tance fore and aft of the unit. The sides of the breakwater adjacent to the walls of the flume were covered with foam rubber to minimize turbulent flow around the ends of the walls as well as friction between breakwater and flume.

The length of the sloping beach is probably the very minimum for which the generaced waves could reasonably be converted from deep to shallow-water waves. It was observed that waves traveling up the beach in the flume were higher than, and out of phase with, waves traveling outside of the flume. Thus, it appears that at least some measure of refraction was achieved by the artuficial beach. Also, it should be noted that the close proximity of the wavemaker to the model sometimes resulted in undesirable interaction between waves reflected from the breakwater and the wavemaker. The redeeming feature in this experimental crudity is the fact that the environmental conditions for the perforated breakwater were always identical to those for the planewall breakwater. That Is, the wave unputs were the same and the physical setup was never altered except that the perforated breakwater was converted to a plane-wall breakwater by the simple expedient of covering the perforated front wall with a plywood sheet.

The tests made at CERC involved a single fixed unit and three floating units all at a scale of 1:27. The fixed unit was installed in the shallow end of the CERC outdoor tank upon a bed of sand about three inches high and extending about a foot on either side of the breakwater. In the floating case, nylon mooring lines were fixed to heavy metal bars resting on the bottom. The waves were varied in period and height while movies were made of wave effects on the structure and on anchored ship models, one seaward and one shoreward of the breakwater (Figure 10). Visual observations of wave effects were also noted and these will be discussed subsequently.

\section{REDUCTION OF DATA}

The waves generated in the Webb Tank were essentially sinusoidal, at the outset. As they traveled through the flume into shallow water, wave shape was altered, the deformation being more pronounced for the longer waves. It was noted in the force records that the oscillations were usually fairly uniform. However, on occasion they were 
irregular or had double peaks and for the highest waves there was often a sudden impact of high force and short duration. These impacts were observed visually as jolts to the system.

As the waves struck the flxed breakwater model, the strain gages recorded the forces in the vertical and horizontal directions. Figure 11 shows a portion of the record of forces and waves associated with a perforated and solid-wall breakw ater for the design wave (13-second period, 15-feet high), which at model scale had a period of 1.93 seconds and a height of 3.83 inches. The input wave (e) is quite long (440 feet full scale) compared with the depth to the bottom (45 feet) so it is not surprising that the trough is shaped as it is. It should be noted that the force traces were recorded at a different speed than the wave trace. Also, the force traces all had different attenuations, hence the ordinate scales are different.

Prior to activating the wavemaker, the force balances were "zeroed" so it was possible to ascertain the magnitude of the force in the upstream and downstream direction (for the horizontal strain gage), and in the up and down direction (for the vertical strain gage). It is important to resolve the total force into these four components, because they affect the breakwater in different ways. Both horizontal components contribute to the overturning moment, depending on their individual magnitudes and phases with respect to the vertical components. The "vertical-up" force acts to dislodge the system from the bottom, while the "vertical down"force tends to imbed it. In general, the "verticaldown" force may be deemed a beneficial effect, while the other three components of force would be detrimental to the system.

To assess the effect of wave forces on the breakwaters being tested, the magnitudes of the different force components were reduced to a common base. That is, the observed forces (Figure 11, a-d) were divided by the appropriate wave heights (in the absence of the breakwater) to produce a graph of force response per unit wave height as a function of wave period. This initial step in data reduction revealed, at once, the expected nonlinear character of the response. Since resolution of nonlinearity is beyond the scope of this program, a pragmatic approach was adopted wherein moderate to large waves were selected, in order to compare results in conditions that would be meaningful from an operational standpoint. The wave inputs used in the analysis are shown in Table III. It should be noted that the design wave specified in this program is included (period 1.93 seconds, wave helght 3.83 inches). 
Table III. Waves Used in Analysis

Period (sec.)

Wave Height

\begin{tabular}{lccc}
\hline Model & Full Scale & Model(inches) & Full Scale(ft.) \\
\hline 0.85 & 5.70 & 3.33 & 12.5 \\
0.99 & 6.64 & 3.83 & 14.4 \\
1.21 & 8.12 & 5.65 & 21.2 \\
1.40 & 9.40 & 5.33 & 20.0 \\
1.53 & 10.27 & 3.73 & 14.0 \\
1.61 & 11.08 & 5.83 & 21.8 \\
1.79 & 12.02 & 3.83 & 14.4 \\
1.93 & 13.00 & 3.83 & 14.4 \\
\hline
\end{tabular}

\section{DISCUSSION OF RESULTS}

Figures 12-21 show the results of the fixed break water experiments. In all cases, the data was plotted to illustrate the relative performance of perforated and non-perforated breakwaters.

Consider Figures 12-15 which compare the horizontal forces on the solid breakwater with those experienced by four different perforated breakwaters. The roman numerals refer to particular breakwater characteristics as given in Table I. It is apparent that all breakwaters exhibit larger horizontal forces (upstream and downstream) for shorter periods, within the period range tested. In general, the solid-wall breakwater experienced greater horizontal forces in all cases except for breakwater III (Figure 14) which has the smallest diameter holes, shortest channel length, shortest distance between walls and the low est solidity ratio. It is expected to be the least effective of all the perforated cases.

Breakwaters I, II, and IV exhibited smaller forces than the solid-wall breakwater on the order of $50 \%$ over most of the period range, although, at higher periods, the solid breakwater performed relatively well. In general breakwater II (Figure 13) gave the best "horizontal" performance. With the exception of one data point (at 10.3 seconds), its behavior was superior to the solid-wall breakwater by a factor of about 2 throughout the entire test range.

Figures 16-19 show the vertical force measurements. It is necessary to consider the up and down vertical forces separately, because the up-vertical force is detrimental while the down-vertical force is beneficial. However, it should be noted that the vertical forces are generally far smaller than the horizontal forces. 
The most striking feature of the up-vertical force graphs is that the solld-wall breakwater exhibits little or no force at low wave periods and relatively large forces at high wave periods. All of the perforated breakwaters experience very little up-vertical force throughout the period range. Again breakwater II appears to be the best with virtually no upward force observed.

The downward vertical force exhibits no distinguishing features. The solid-wall breakwater shows the greatest overall force in this direction but the magnitude is again small compared with the horizontal forces. Even so, this is a beneficial force and should not be neglected.

In summary, it is found that three of the four perforated breakwaters exhibit clear superiority over the solıd-wall breakwater in the matter of horizontal forces and upward vertical force. In particular, perforated breakwater I I achieves force reductions on the order of $50 \%$ in these directions. The solid-wall breakwater is generally superior to all the perforated breakwaters in the matter of downward vertical force, although this force is relatively small.

It was suggested that the desirable down-vertical force could be increased if the front wall were inclined out and dow $n$ with respect to the back wall. Using the characteristics of breakwater I and a slope of about $30^{\circ}$, with the channels horizontal, breakwater VI was constructed and tested against a solid-wall breakwater at the same inclination. The results appear in Figures 20 and 21.

The horizontal forces on the inclined breakwaters (Figure 20) were about the same as for the vertically-oriented breakwaters (Figure 13). The vertical forces, however, changed significantly. The upward vertical forces (Figure 20) became as much as six times larger than they were before inclination. However, for the perforated case, these were still small compared with the horizontal forces. The beneficial downward forces increased about five-fold to about the same magnitude as the horizontal forces. It is not clear, at this time, whether anything has been gained by increas ing both the up and down forces in the vertical direction. It may be that the increase in up-vertical for the perforated breakwater is small enough to make the increase in down-vertical truly beneficial; this remains to be proved.

These experiments on fixed breakwaters indicate that the perforated breakwater generally experiences smaller detrimental forces than the solid-front or caisson-type breakwater. One particular perforated configuration (I I) appears to be signuficantly superior by at least a factor of two. This is not meant to be an all-inclusive figure of merit but is specifically directed to the given "design wave" 13 seconds, 15 feet high). Final pronouncement of merit should be based on more 
sophisticated experimentation (three-dimensional tests in regular and irregular waves).

\section{FLOATING-MOORED BREAKWATER}

Once it was concluded that perforated breakwater II (Table I) was most effective in dissipating wave energy, when the breakwater was mounted on the bottom, that configuration was used for the floatingmoored tests. Figure 9 shows a drawing of the test section for the floating case. There are four strain gages, two in mooring lines on the seaward side of the breakwater and two in the mooring lines on the shoreward side. In addition, the motions are monitored by linear accelerometers (horizontal and vertical) mounted on the back wall of the breakwater. These six variables were recorded as a function of incident wave period and wave height which were measured seaward and shoreward of the breakwater. The strain gage measurements relate to the structural integrity of the system; the accelerometer measurements, as indices of breakwater motion, should verify the observations of wave attenuation behind the breakwater.

As in the case of the fixed breakwaters, the results on the floating units were found to be highly nonlinear. In fact, the solid-wall unit was observed to strike the bottom of the flume on a number of occasions. For the sake of uniformity, the numerical analysis was carried out in the same way as for the fixed case and for the same input waves (Table III).

Figures 22-25 show the results of the forces experienced in the mooring lines. It is immediately evident that the perforated breakwater experiences significantly less force in all of the lines. The amount varles considerably from line to line (identical intial mooring tension in every line was not attempted) and from wave to wave. However, it is seen that the minimum force reduction was $10 \%$, in one case, whlle the maximum force reduction was about $90 \%$ in another case. At the design wave ( 13 seconds), the forces on the lines of the solid-wall breakwater are considerably greater.

The attenuation of waves by the breakwaters was defined as the ratio of the wave height shoreward of the breakwater to the wave height at the same location, in the absence of the breakwater. This measure of wave reduction is associated with the initially generated waves as shown in Table II. The results appear in Figures 26 and 27.

For the perforated breakwater (Figure 26), it is clear that wave attenuation is most effective at low periods and least at high periods. And, in particular, the design wave (13 seconds, 15 feet) is only reduced to about 9 feet which is far from the required reduction to 4 feet. In 
contrast to the perforated breakwater, the floating caisson type (Figure 27) exhibits no obvious frequency dependence; attenuation is fairly uniform (albeit widely scattered) across the range. Reduction of the design wave to about 5.5 feet is better than that achieved by the perforated breakwater but still not satisfactory. Figure 28 compares the wave attenuation performance of the two breakwaters through the ratio of their observed wave heights behind the breakwater. Thus, values less than one indicate that the perforated breakwater is more effective in attenuating waves and values greater than one show the superiority of the caisson type. It is clear from Figure 28 that the perforated unit is better up to about 9 seconds and worse beyond.

Results of measurement of horizontal and vertical accelerations appear in Figures 29-31. About all that can be said, from inspection, is that the component accelerations are of the same order of magnitude for the perforated and solid-wall breakwaters and this in itself tends to support, in a very general way, the results on wave attenuation.

The experiments carried out at CERC were essentially qualitative in nature, but rather revealing nonetheless. The bottom-mounted breakwaters (about 10 feet long) were installed on a bed of sand about 3 inches high and extending about a foot shoreward and seaward of the unit. They were fixed to the bottom by placung heavy weights in the chamber between the front and back walls. After a number of different waves were propagated down the tank, for about 5 minutes, it was observed that all the sand on the seaward side of the calsson type had been scoured out and the entire unit had been displaced about one foot shoreward. The perforated unit was not disturbed at all nor was there any sign of scouring.

In the floating case, three units were placed side by side and spaced about 13 feet apart (full scale). The moorings were nylon lines fastened to heavy rails laid on the bottom. Similar ship models were anchored shoreward and seaward of the breakwaters and about $45^{\circ}$ to the incident waves (Figure 10). It was observed that after several minutes of wave propagation, the lines on the solid-wall breakwater became rather slack and the rails had to be returned to their previous positions. This did not occur with the perforated units. It was, however, not obvious that the waves on the shorew ard side were smaller for the perforated breakwater. In fact, for both types of breakwater, it was not obvious that the waves on the shoreward side were appreciably smaller than on the seaward side.

In order to reduce the motion of the breakwater units, and thus reduce wave generation shoreward, the mooring was modified by addstion of 4 lines extending vertically to the bottom from the corners of each unit. Also, a solid bottom was installed. The results of these 
actions was to reduce the waves shoreward of the perforated breakwater system to such an extent that for extreme waves the ship model on the seaward side was completely swamped while the shoreward ship model remained relatively dry. Furthermore, it was noted that wave height was manifested by a wetting on the tank side walls; the height of "wavewettıng" was significantly lower on the shoreward side of the breakwater, in this case.

Although the limited tests at CERC did not permit variation of the distance between breakwater units, the one condition tested did not exhibit much diffraction through the gaps between units. Diffraction was considerable at the ends of the three-unit system, but when a fourth unit was added, covering the width of the tank, diffraction effects were reduced considerably.

\section{CONCLUSIONS AND RECOMMENDATIONS}

The purpose of the study reported here is to determine whether the concept of a perforated breakwater holds promise as a potentially useful tool in amphubious operations. In particular, it was essential to determine whether the perforated breakwater is 11kely to perform better than the calsson-type. "Better performance" is not specified in a quantitative way. It is presumably sufficient to demonstrate that the forces experienced by the perforated breakwater are significantly smaller than on the caisson-type, when bottom-mounted. When floating and moored, the mooring-line forces should be less for the perforated case and, most important, a 13-second, 15-foot wave should be reduced to 4 feet shoreward of the breakwater.

In general, the following conclusions can be draw $\mathbf{n}$ wth regard to the bottom-mounted breakwater:

1. The breakwater geometry specifying: 4-foot diameter holes, 4 -foot wall thickness, and 40 feet between front and back wall was found to be most effective, as predicted by theory.

2. The best perforated breakwater experiences less force overall than the solid breakwater. The degree of superiority varies with the direction of force application (horizontal, vertical) and wave period. Greater effectiveness was usually found at lower wave periods except for the very important upward vertical force where the solld breakwater experienced forces greater than 11 times that of the perforated breakwater, at the design wave ( 13 seconds, 15 feet).

3. Inclination of the front wall to increase the beneficial downward force showed such an increase by a factor of about 5 . But the 
upward force increases six-fold, so there is no conclusive evidence of an advantage gained there.

4. The perforations appear to create a stable environment for the bottom sediment while the caisson-type produces considerable scouring at the base of the front wall.

It appears that the bottom-mounted perforated breakwater has demonstrated its superiority over the caisson-type. However, it may be worthwhile to reduce the force still more, especially if there is little penalty to be paid. The simple expedient is to perforate the back wall and thereby reduce the pressure there. The perforations should probably extend from a little below the waterline to the top of the breakwater. It is recommended that an analytical study be undertaken to determine the expected force reduction due to different sinusoidal inputs when the hole-size and spacing are varied. The extent of the perforations on the back wall must also be determined and the theoretical results should be verified by model experiments.

From the experiments on the floating-moored breakwaters, the following general conclusions are drawn:

1. The perforated breakwater experienced less force in the 4 mooring lines. Again, the degree varied being just slightly less in one instance and one-tenth of the force in the mooring line of the solid breakwater in another. Overall, a factor of 2 in force reduction might be assigned, but there is considerable scatter about this figure.

2. At the design wave, the mooring lines in the perforated breakwater experienced less force by about a factor of 2 .

3. Wave reduction by the solid floating-breakwater varied from about 0.2 to 0.6 . For the perforated floating breakwater, wave reduction varied from about 0.2 to 0.8 . As expected, the perforated breakwater was far more effective in reducing wave height for shorter waves (0.1 to 0.3$)$ than for longer waves $(0.6$ to 0.7 ). How ever, the perforated breakwater failed to reduce the height of the design wave to the level specified.

4. The motion of the breakwaters as measured by horizontal and vertical accelerations showed no clear superiority and this was reflected in wave reduction behind the breakwaters.

The work at both Webb and CERC showed that the floating perforated breakwater was effective in reducing wave height as well as force. Nevertheless, it is necessary for greater wave reduction capability to 
be designed into the breakwater system, if it is to meet the stringent requirements given in the Introduction.

It is evident that the mooring arrangement influences the "rolling ${ }^{\prime \prime}$ motion and hence the waves generated behind the breakwater. Consequently, an optimum mooring arrangement must be devised whereby motion is minimized without sacrifice of minimum mooring-line force. Figure 32 shows several mooring arrangements that might be consider m ed. The top system has already been tested. The others show promise of restraining motion. They should be studied as physical systems subjected to oscillatory force inputs to determine which 1s likely to produce the least rolling motion. The best of these should be tested in the twodimensional tank to determine the most effective mooring arrangement.

The next step in evaluation is to determine the effectiveness of the bottom of the breakwater in reducing motion. The two-dimensional experiments at Webb were made without a bottom while the CERC study included both a perforated and solid bottom. The solid bottom appeared to reduce the waves more, but eyes are not to be trusted. A study of different bottoms (for the best mooring arrangement) should reveal another aspect of motion and wave reduction that will influence the final design.

The last phase of design optimization for the floating breakwater involves perforating the back wall (as in the case of the fixed breakwater) to further reduce rolling. This will be associated with the best conditions achieved in the preceding tests. The net result will be a final basic design for the unit breakwater that hopefully combines achievement of wave reduction, as specified, with a substantial force reduction in the mooring lines as compared with the solid breakwater. It goes without saying that two-dimensional tests should be made to vertfy the expected performance.

Once the optimum design for the breakwater unit is determined, it is essential to evaluate its performance as an operational entity. This means testing of 5 unit breakwaters in a three-dimensional tank, such as at Stevens Institute of Technology. This would include a variety of wave conditions, and, if physically possible, at least one variation in direction of incident waves. In particular, a series of irregular wave forms corresponding to different states of sea, should be used. From this data, spectral analysis will reveal the nature of structural and wave damping effectiveness in moderate and storm conditions, without regard to the nonlinearity of the system.

If such a program is successful, it will culminate in a final basic design for the complete breakwater system (fixed and floating) including all aspects of breakwater geometry and mooring arrangement. 


\section{ACKNOWLEDGMENTS}

The work carried out under this program could not have succeeded without the help and cooperation of many individuals and organizations.

The U. S. Naval Facilities Engineerıng Command, Washington, D. C., encouraged and supported the work. In particular, Captain E. G. Cunney, Fred Knoop and Pat Cave provided assistance with various aspects of the program.

The Webb Institute of Naval Architecture, in the person of Prof. E. V. Lewis, was most generous in the use of its tank faclities, and different staff members and students were almost always about to lend a hand. The staff of the Coastal Engineering Research Center was equally helpful during the time spent there. The U. S. Navy Civil Engineering Laboratory supplied the breakwater models for the threedimensional tests and the David Taylor Model Basin loaned us two ship models.

On the home front, G. E. Jarlan, inventor of the perforated breakwater concept, constantly supplied valuable suggestions and participated in the CERC tests. Mr. A. F. Lehman, head of the OCEANICS Water Tunnel Division, contributed to the practical engineering aspects of the design. Messrs. Bert Kleffer and Bob Romandetto assisted in the experimentation. In addition, Mr. Kieffer prepared all the design drawings as well as the figures in this paper. Mrs. Pat Gallo typed the manuscript.

\section{REFERENCES}

Bulson, P. S. (April, 1964). Transportable breakwaters, A feasibility study: Report Res. 42./1/4, Military Engineering Experimental Establishment, Christchurch, England.

Jarlan, G. E. (April 1965). The applucation of acoustic theory to the reflective properties of coastal engineering structure: DME/NAE Quarterly Bulletin No. 1965(1), National Research Council of Canada

Jarlan, G. E. and Marks, Wilbur (March 1965). Optimum hydrodynamic characteristics of a stable ocean platform for deep-sea operations: Tech. Note No. 65-07, Oceanics, Inc.

O'Brien, J. T.; Kichenreuther, D. I.; and Jones, R. E. (April 1961). Mobile piers and breakwaters - An exploratory study of existing concepts: Tech. Rept. 127, U. S. Naval Civil Engineering Lab., Port Hueneme, Calif. 

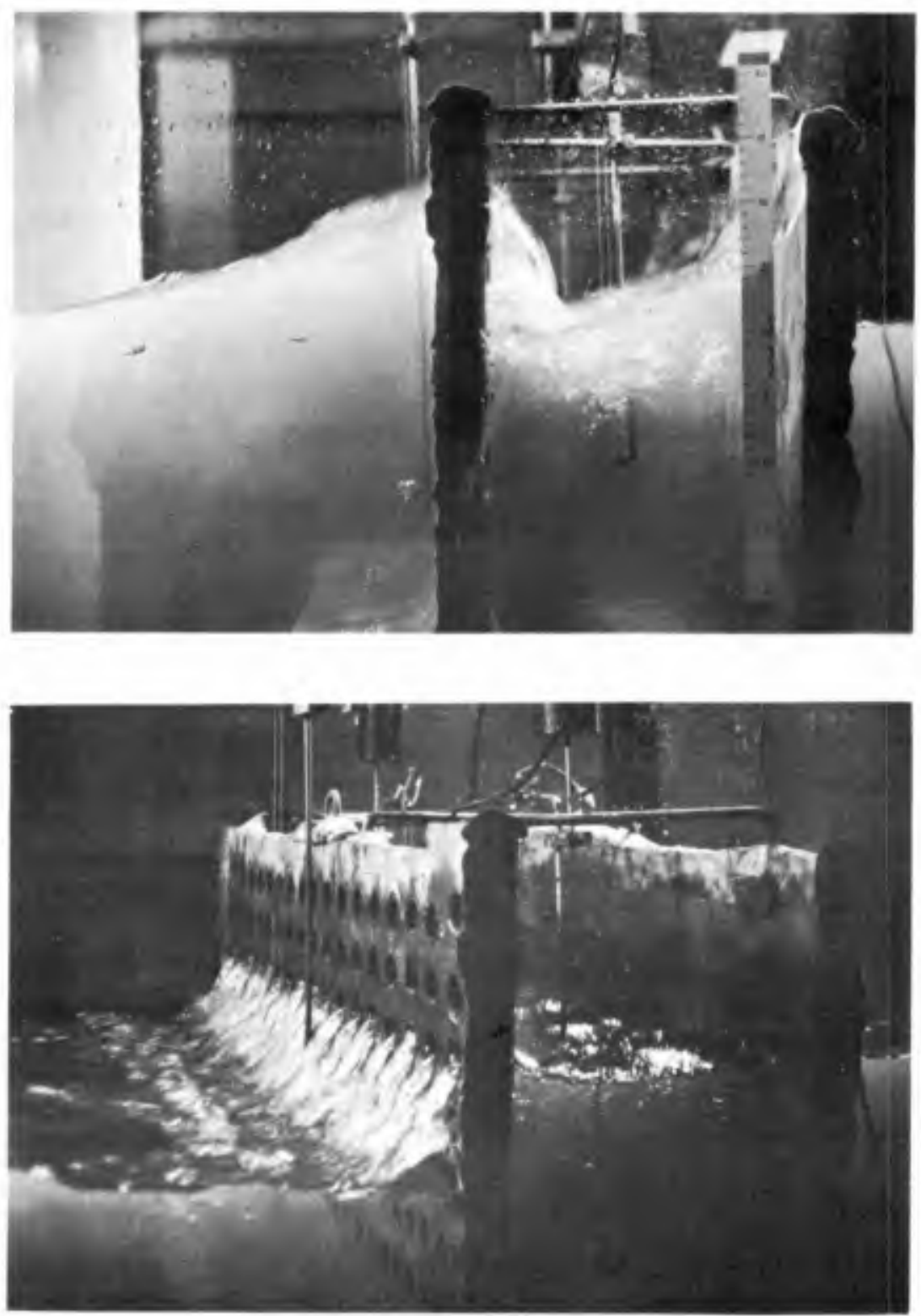

Fig. 1. Model of waves incident on a perforated wall and return flow (National Research Council of Canada). 


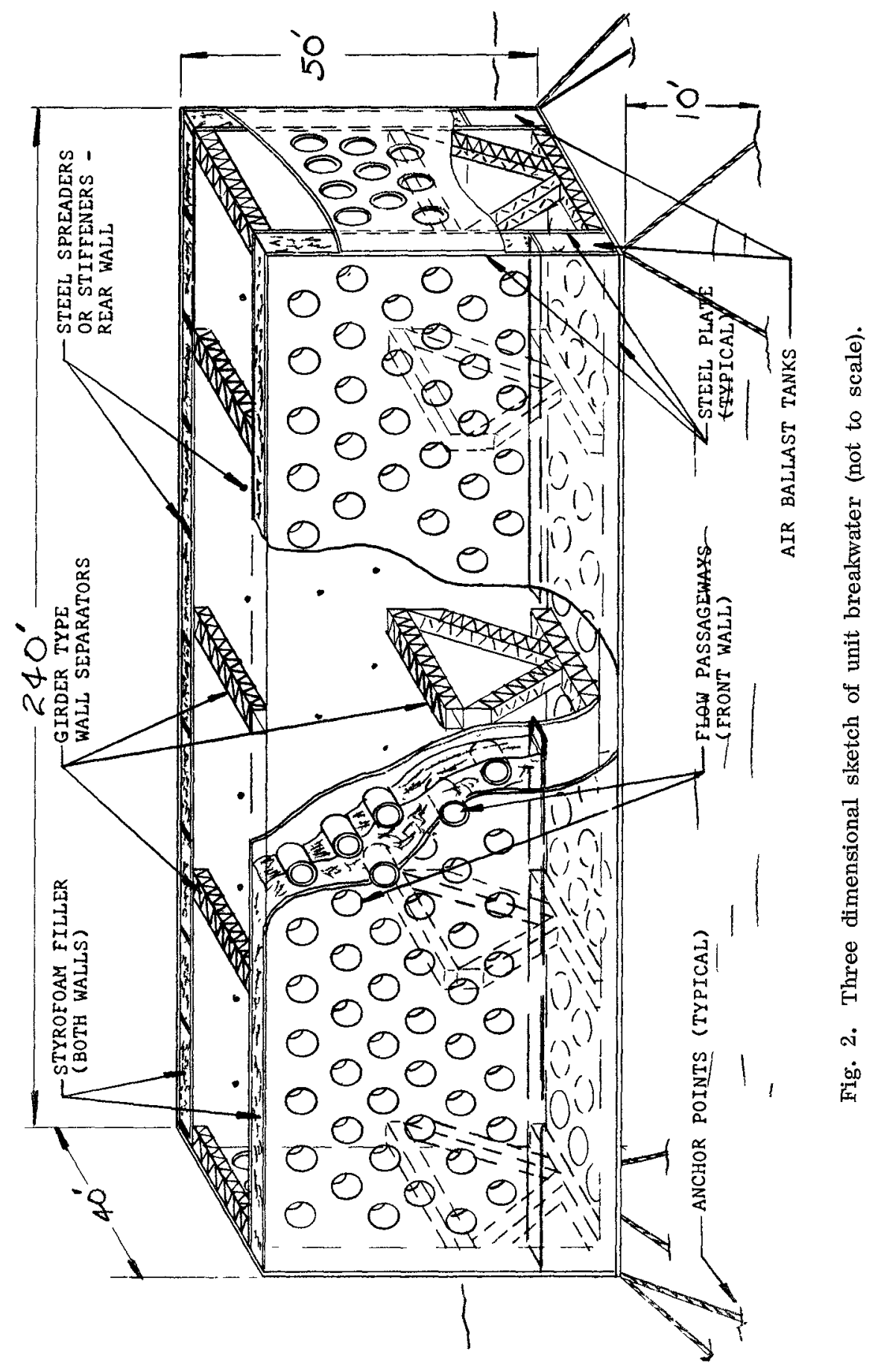




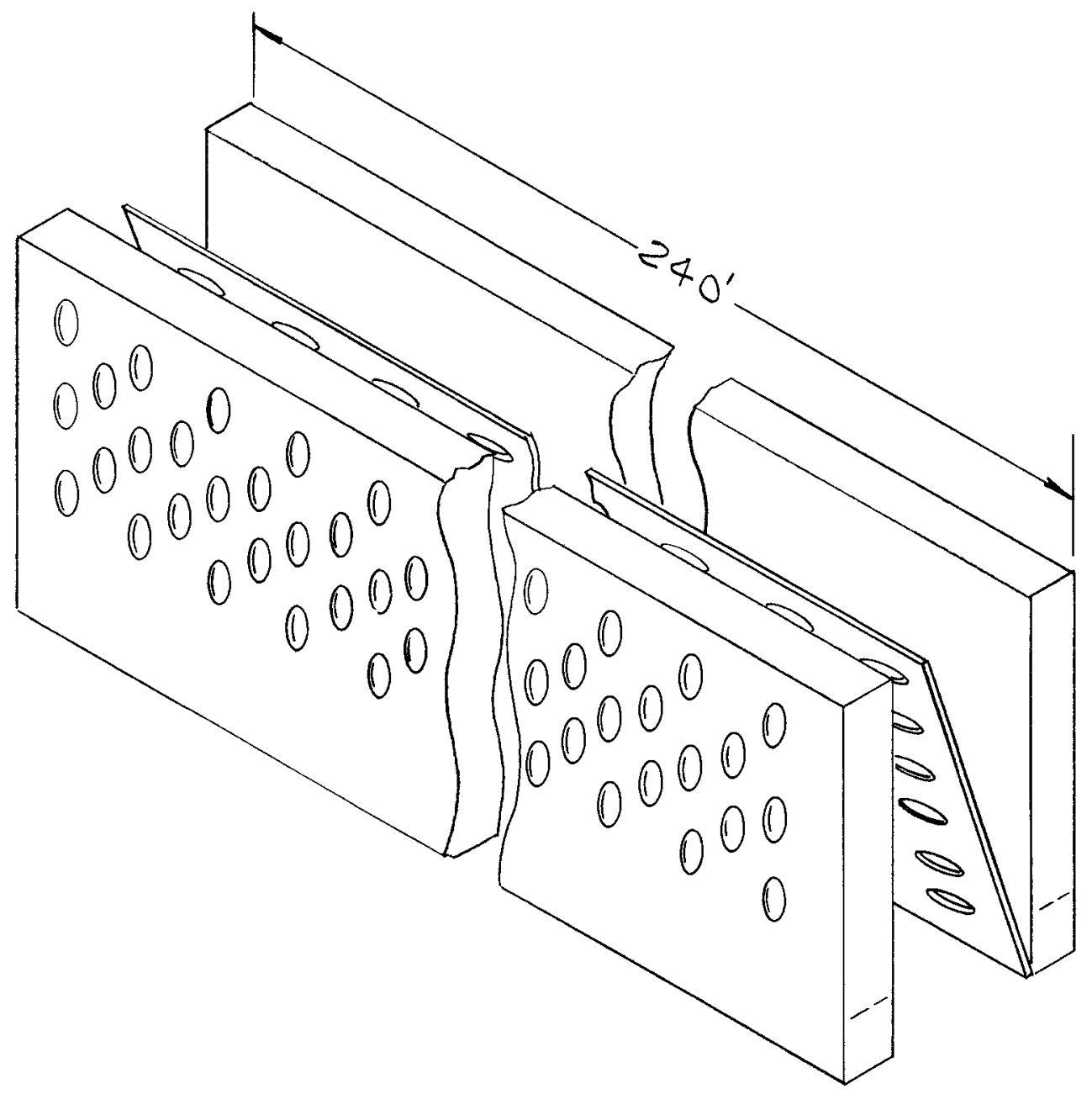

Fig. 3. Unit breakwater prepared for towing. 


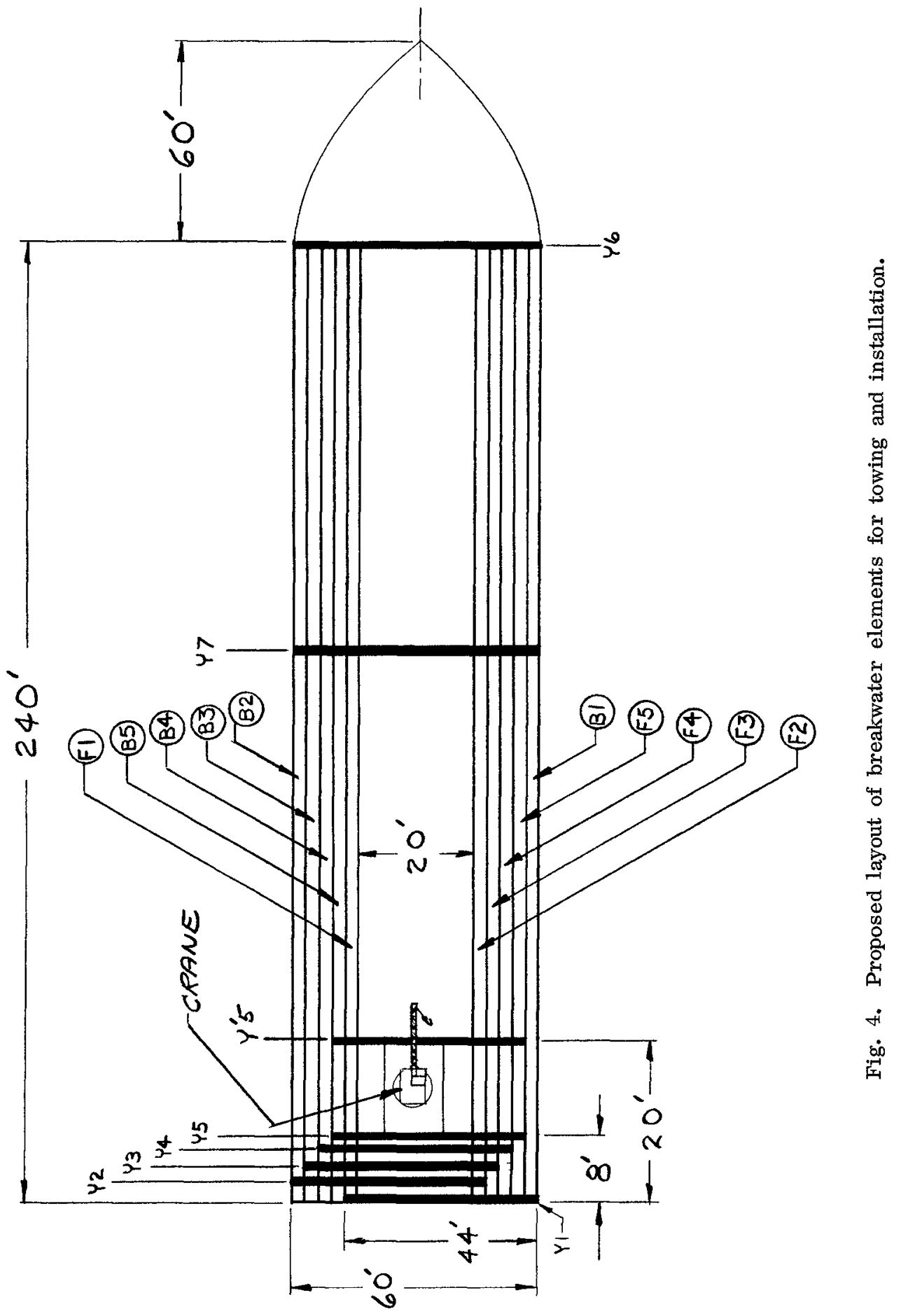




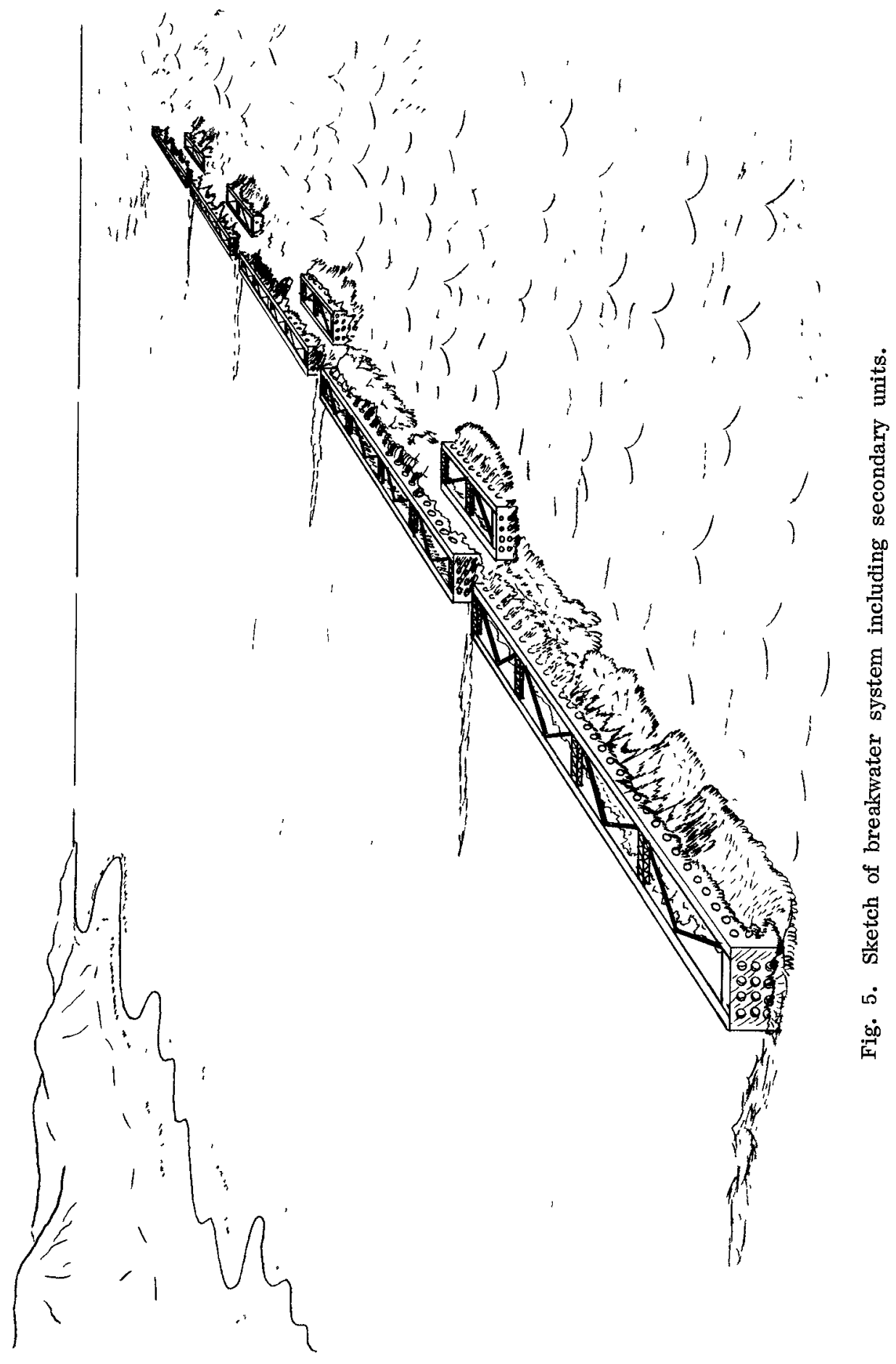




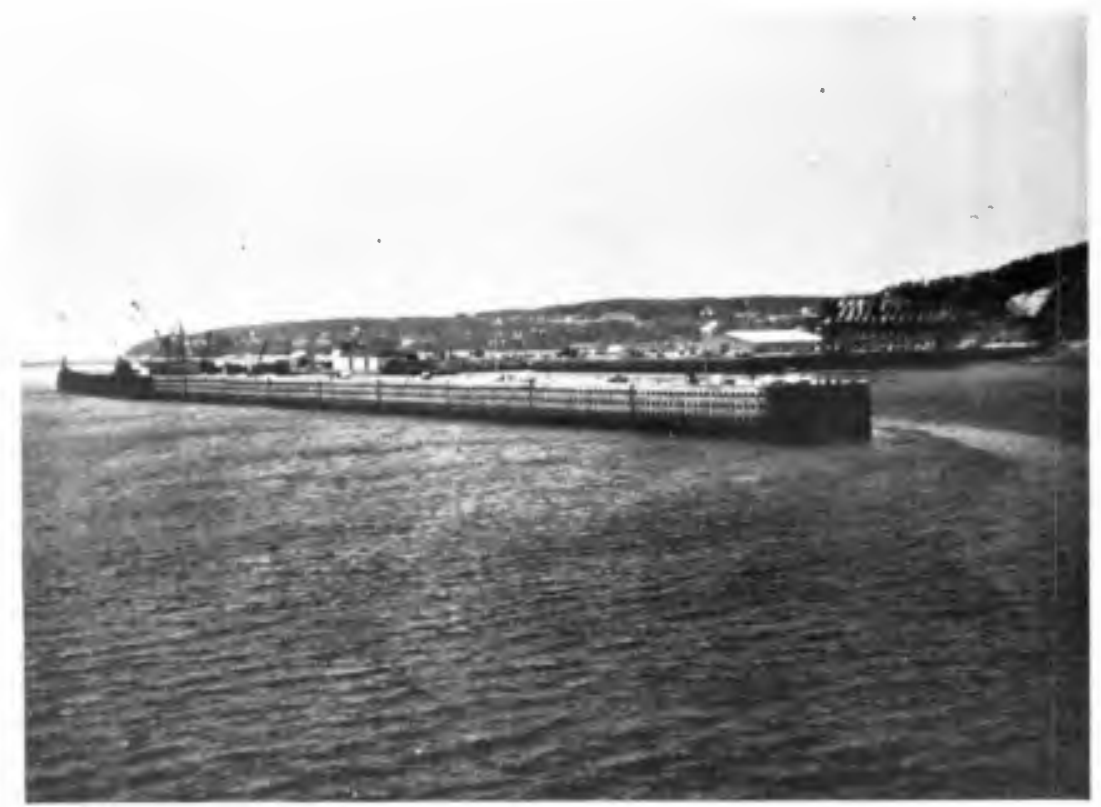

Fig. 6. Baie Comeau harbor breakwater (National Research Council of Canada).

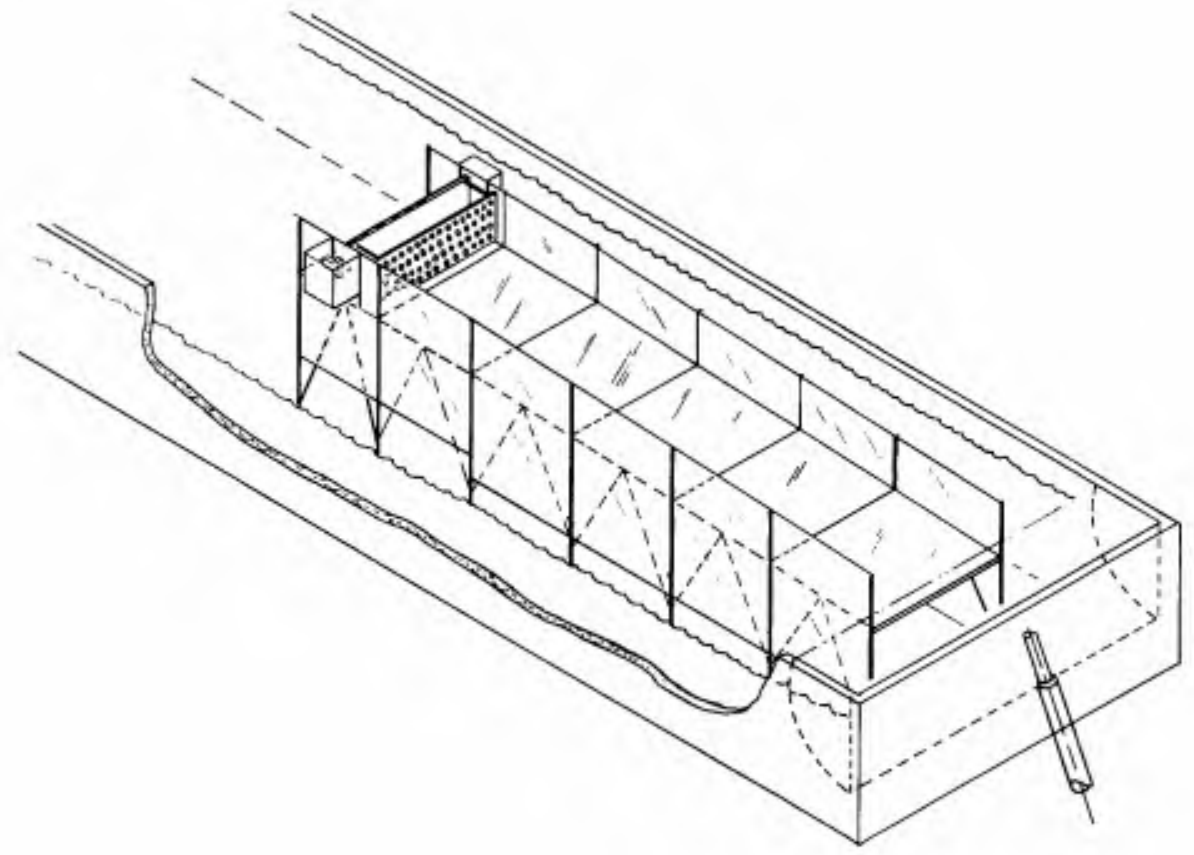

Fig. 7. Sketch of Oceanics shallow-water flume in wave tank. 


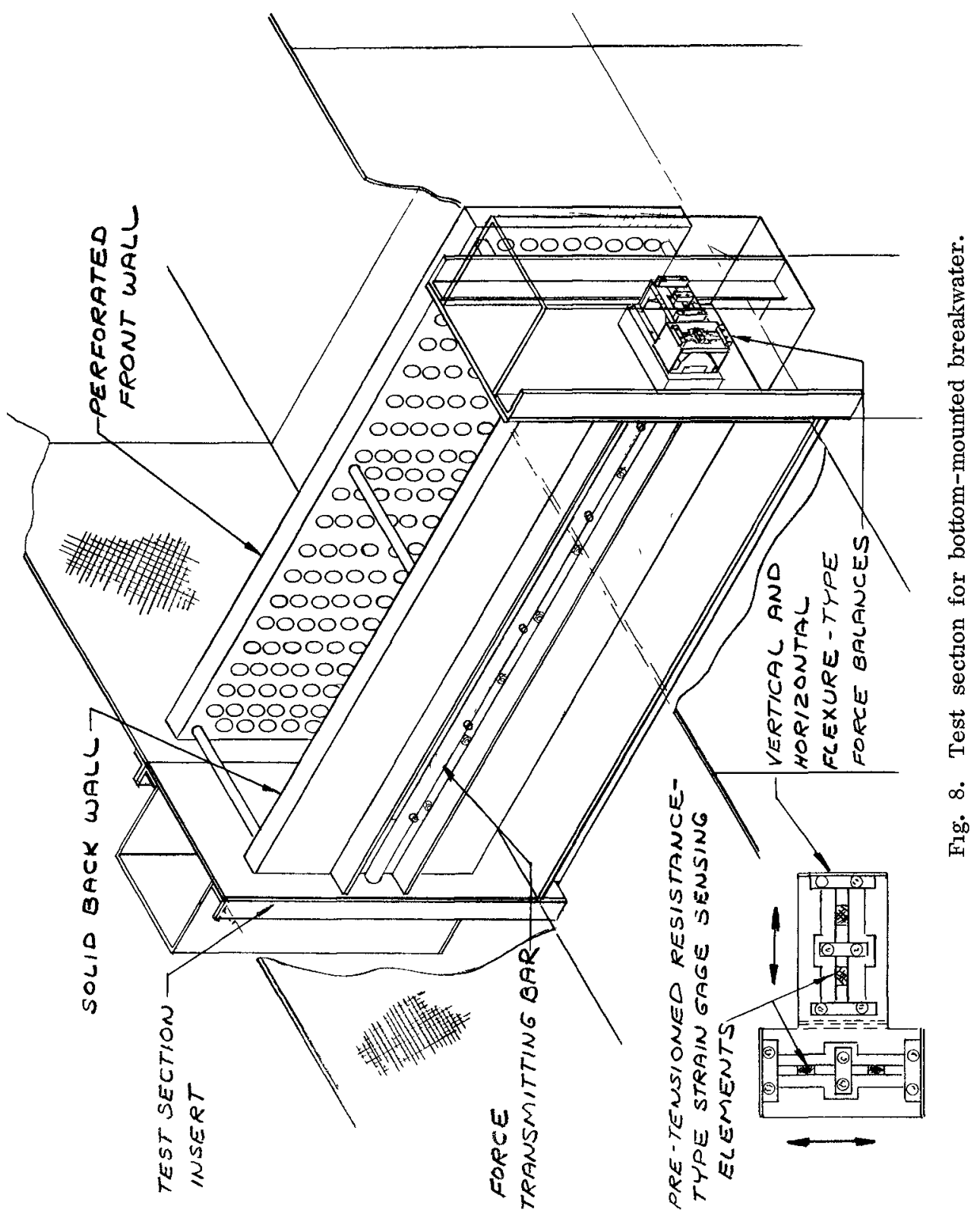




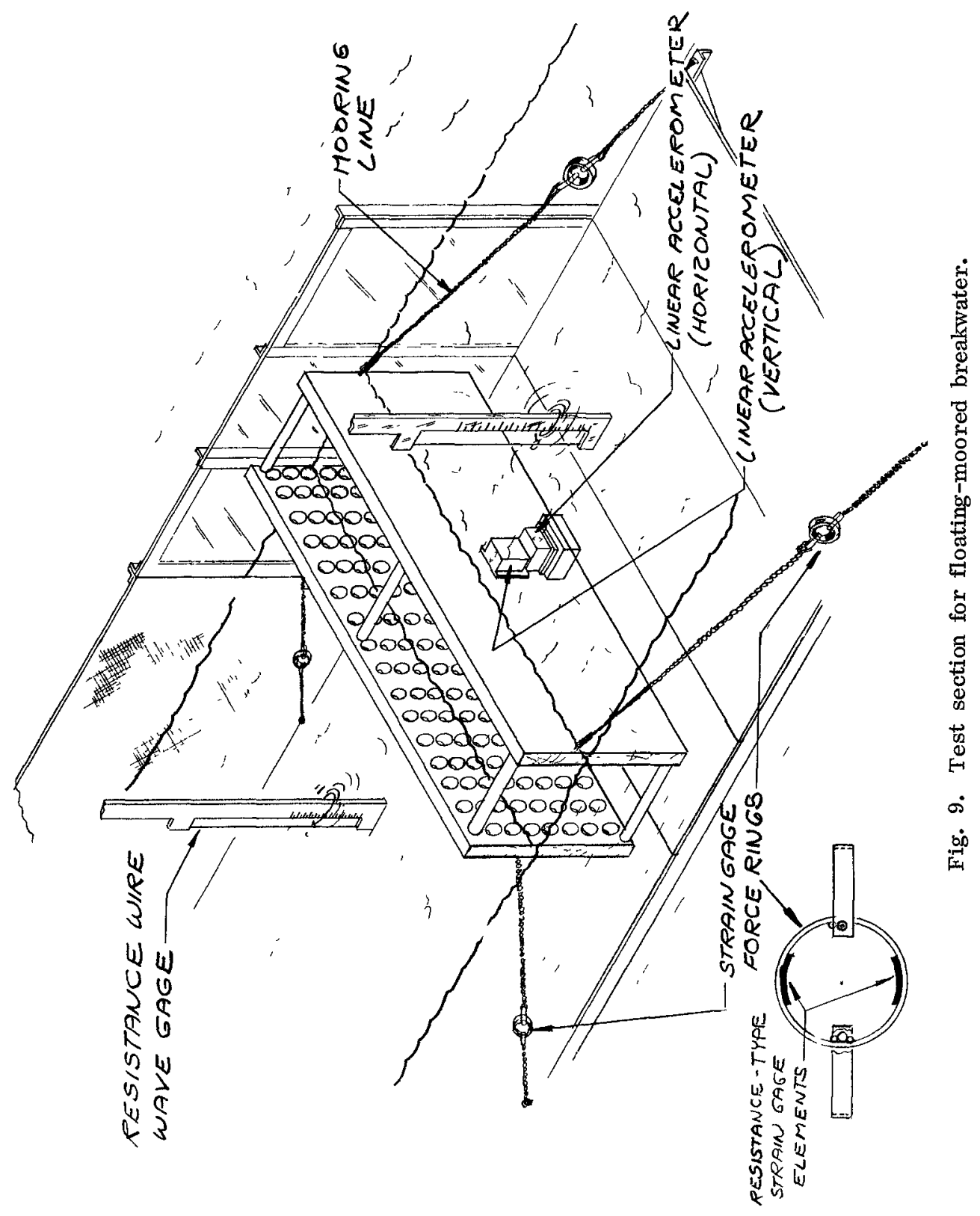




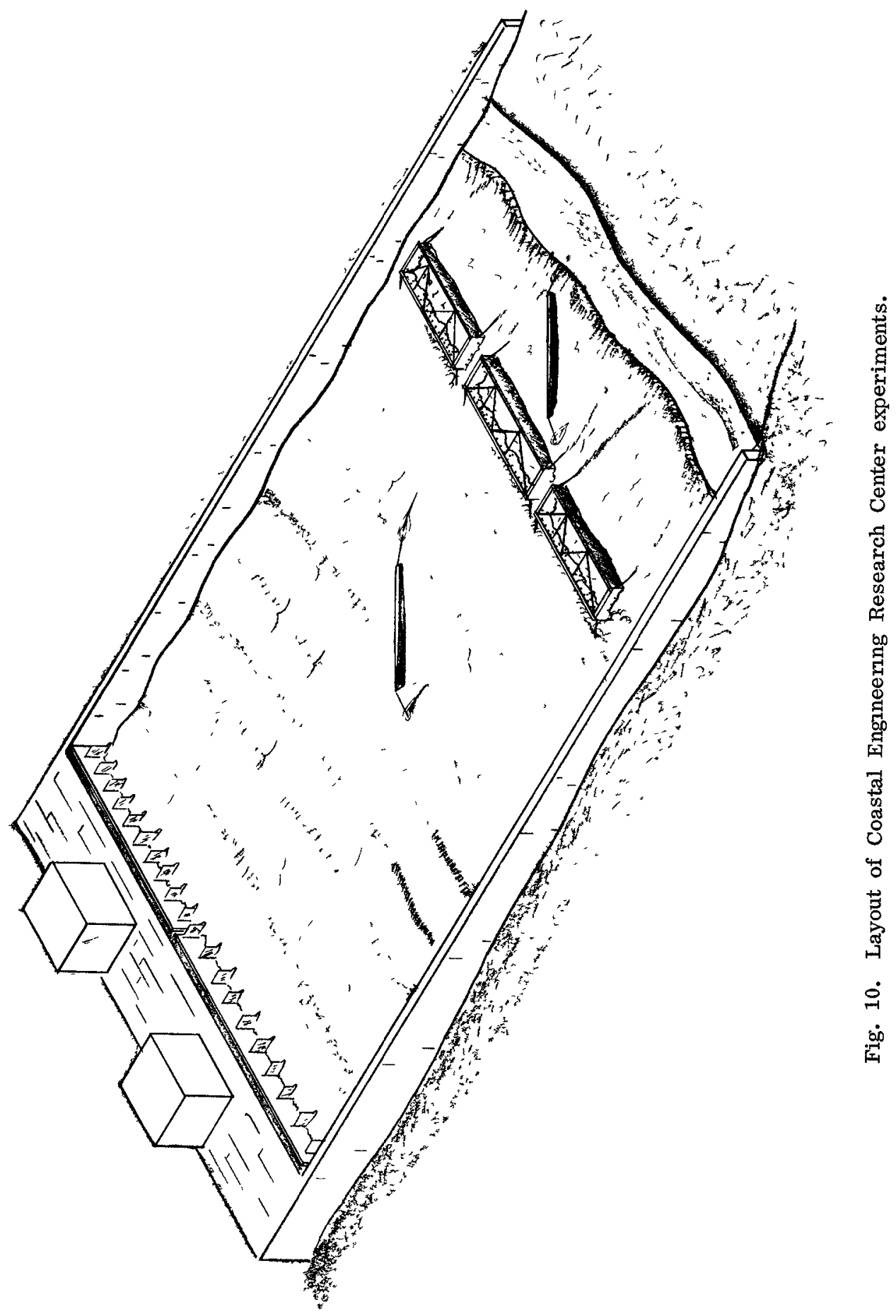


(a)

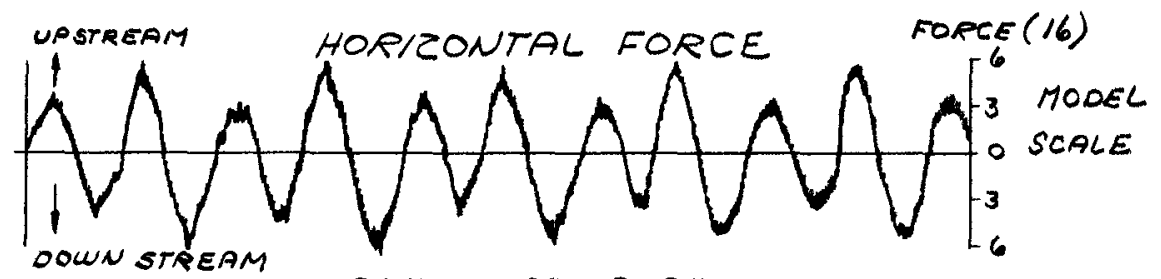
BREAKWATER II

(b)

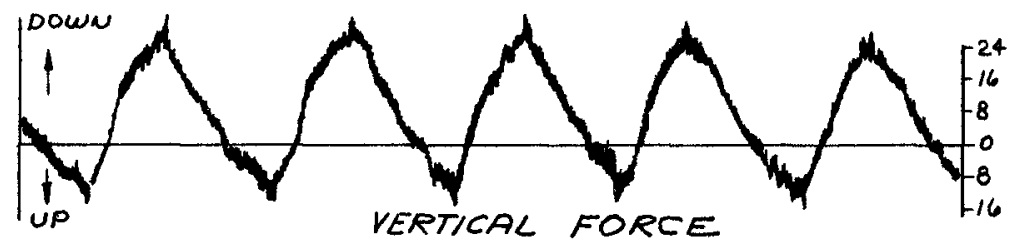

(c)

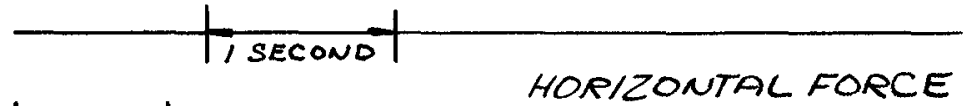

(d)

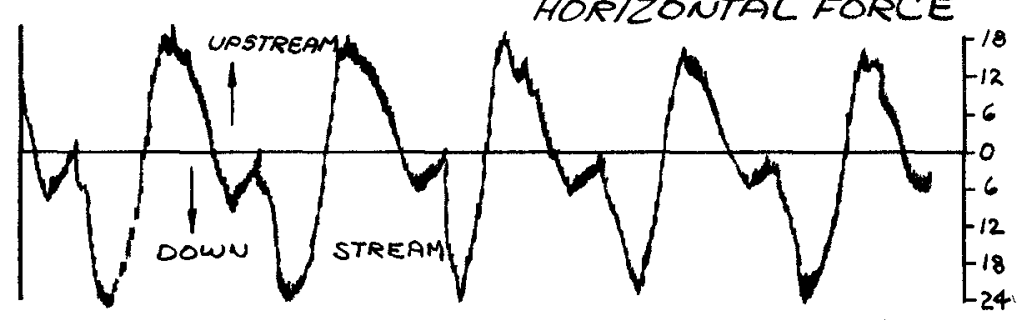

BREAKWATER I

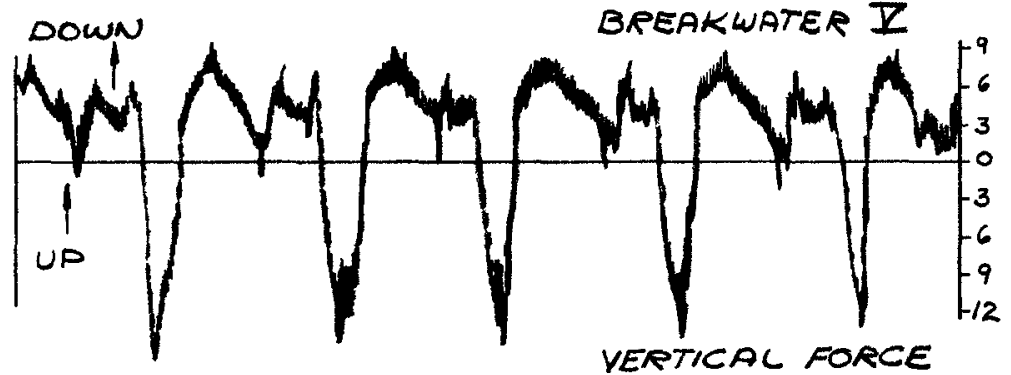

$$
\text { HEIGHT (FT) }
$$

(FULC SCALE)

WAVE

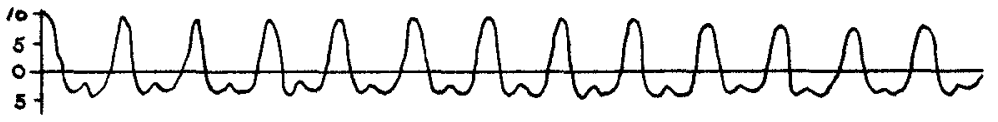

(e)

$$
1 \frac{1}{5 \sec )^{-1}}-1
$$

Fig. 11. Portion of records showng forces on a fixed perforated breakwater (II) and solid breakwater (V) for the design wave. 


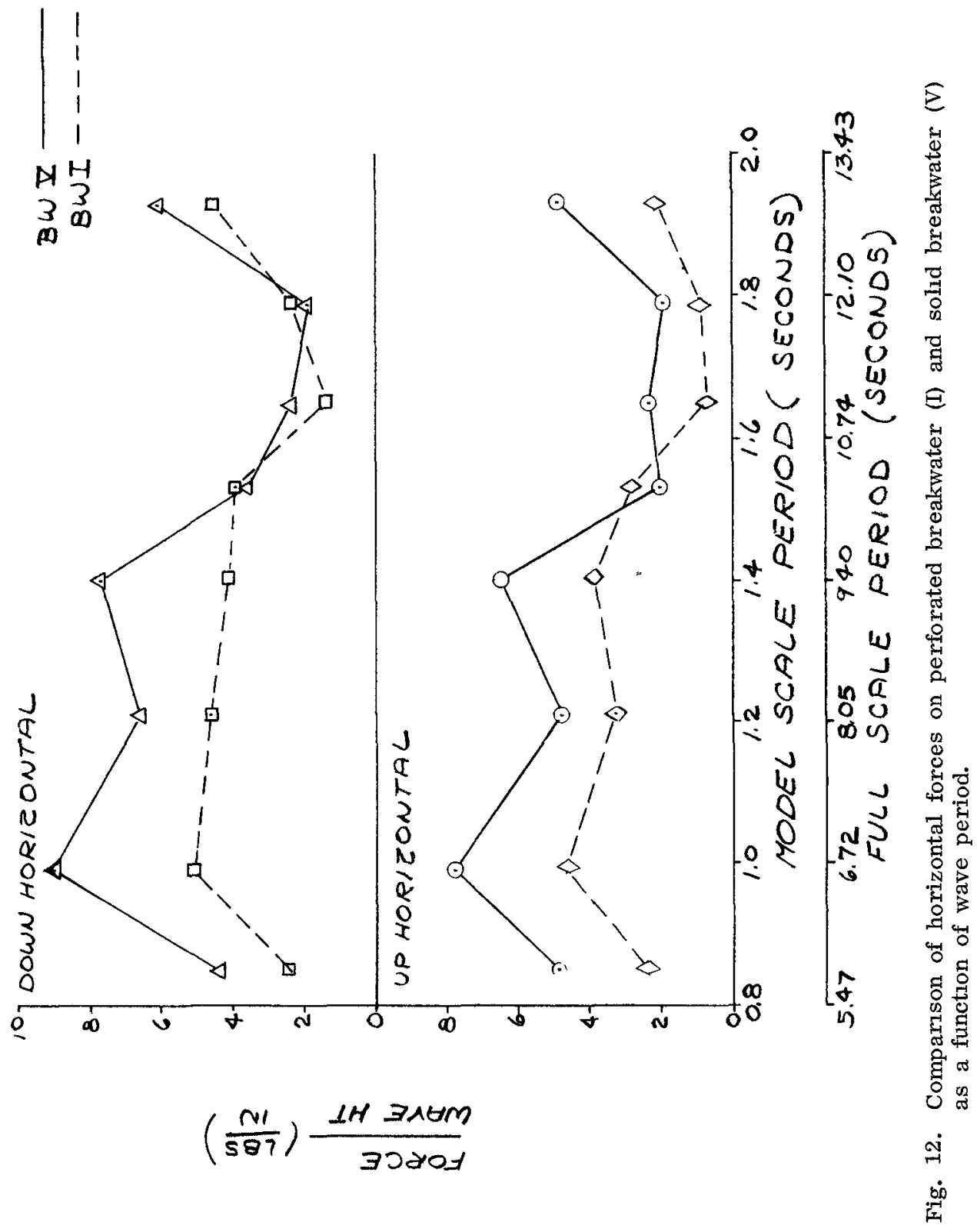




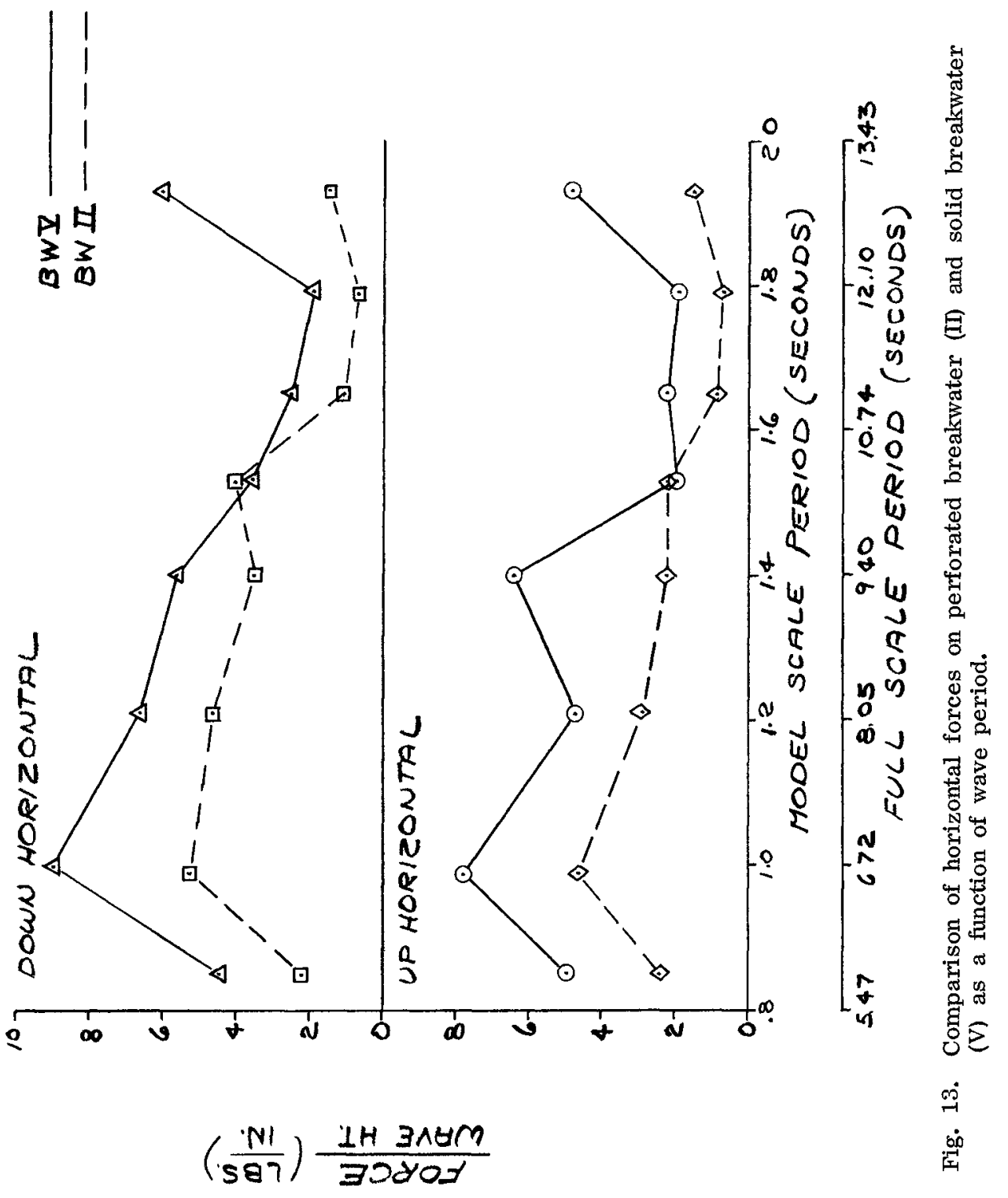




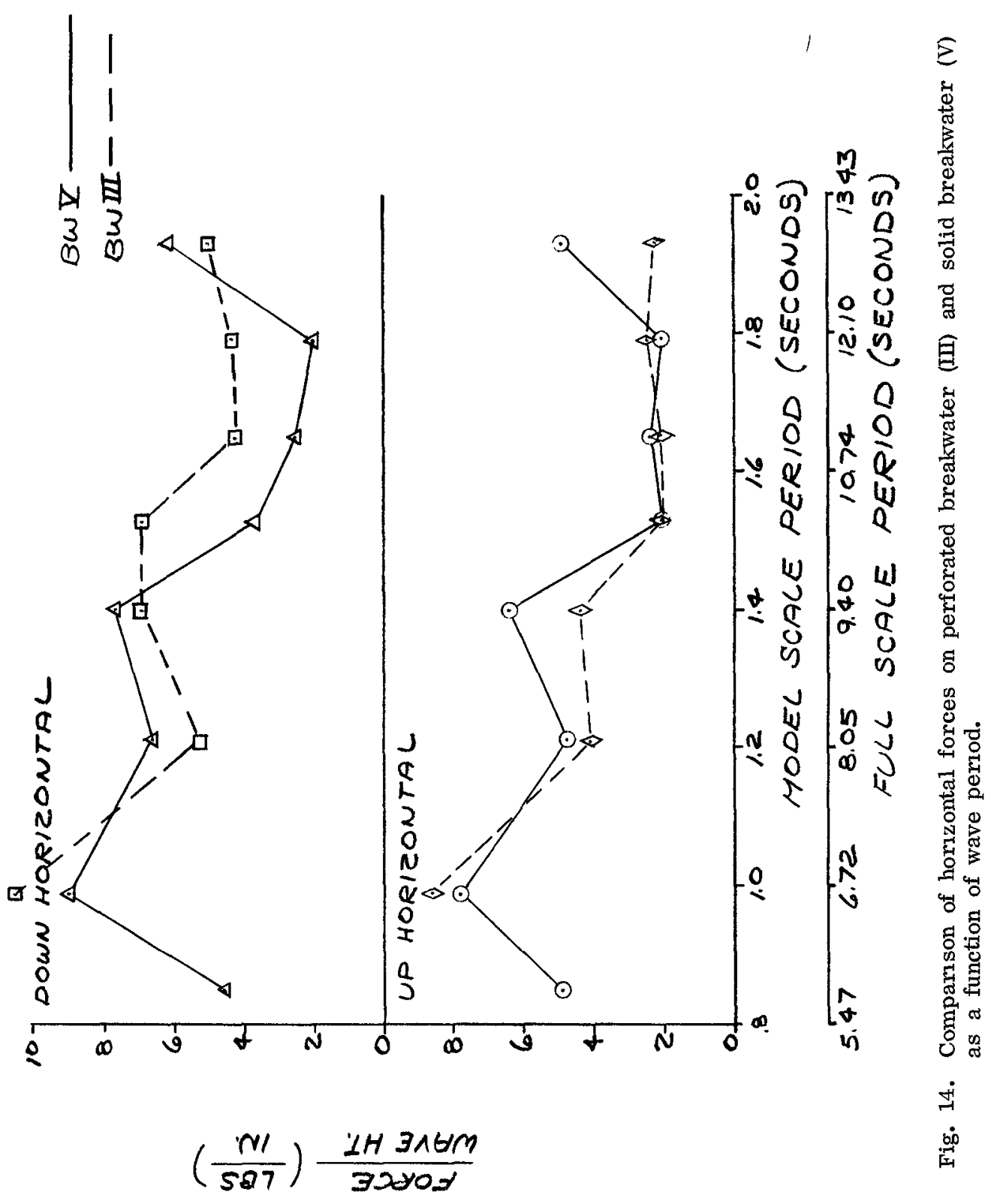




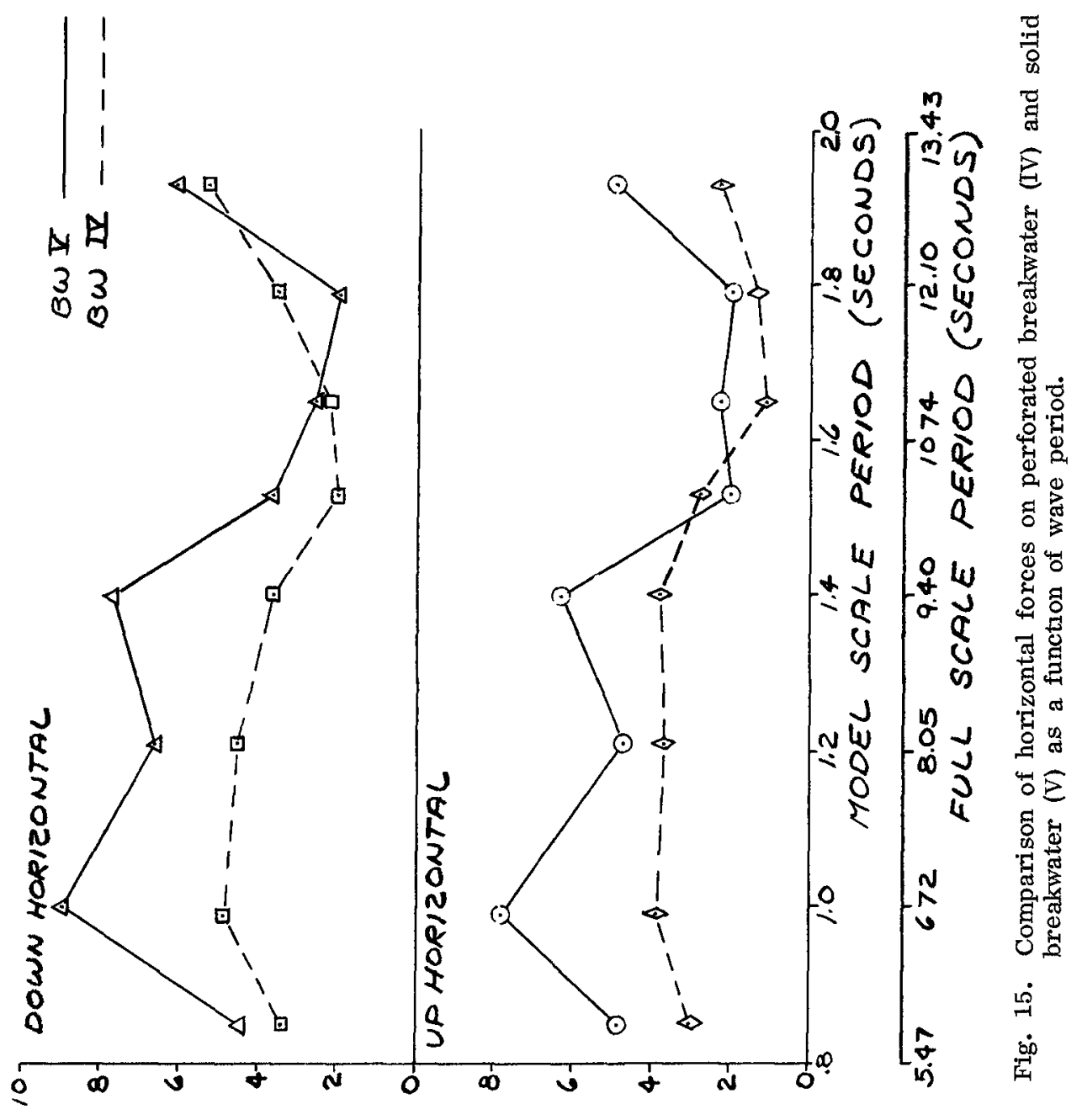

$\left(\frac{N 1}{597}\right) \frac{1 H 316 m}{35007}$ 


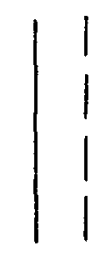

$\begin{array}{ll}1 & 4 \\ 3 & 3 \\ 0 & 0\end{array}$

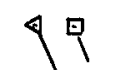

(1) 40

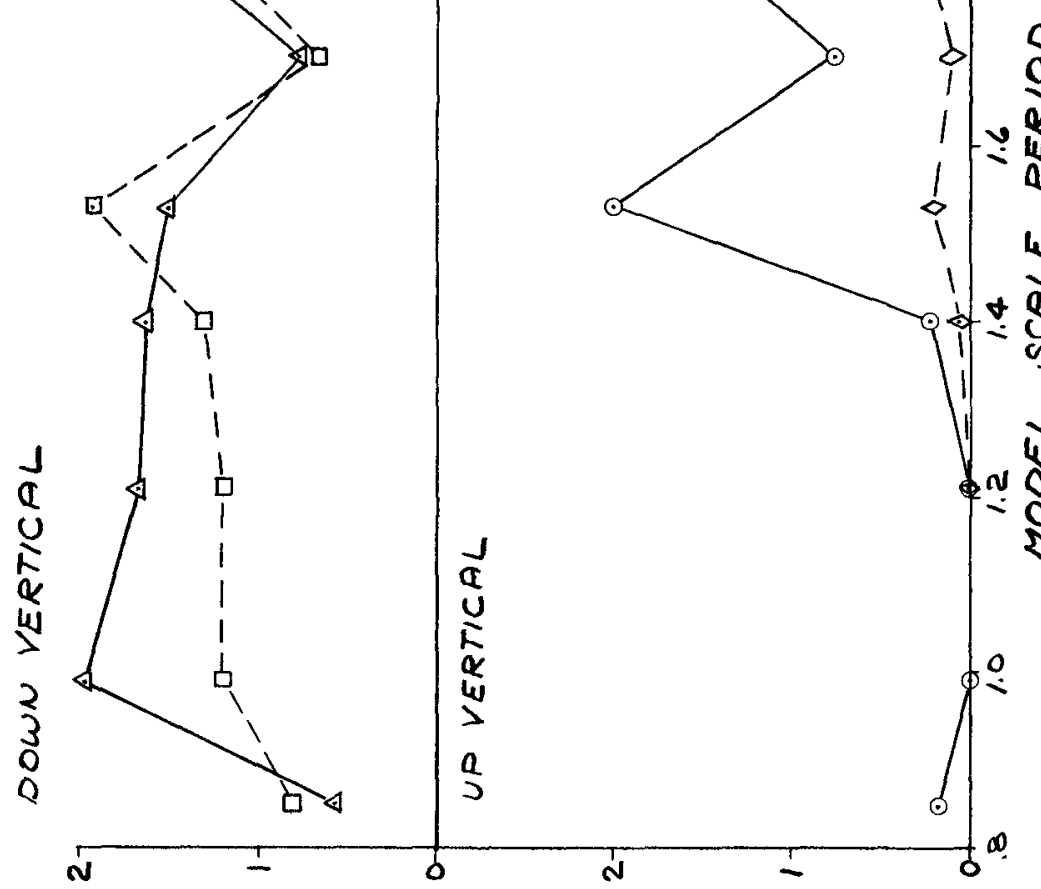

㠃

용

్ㅗㅀ

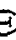




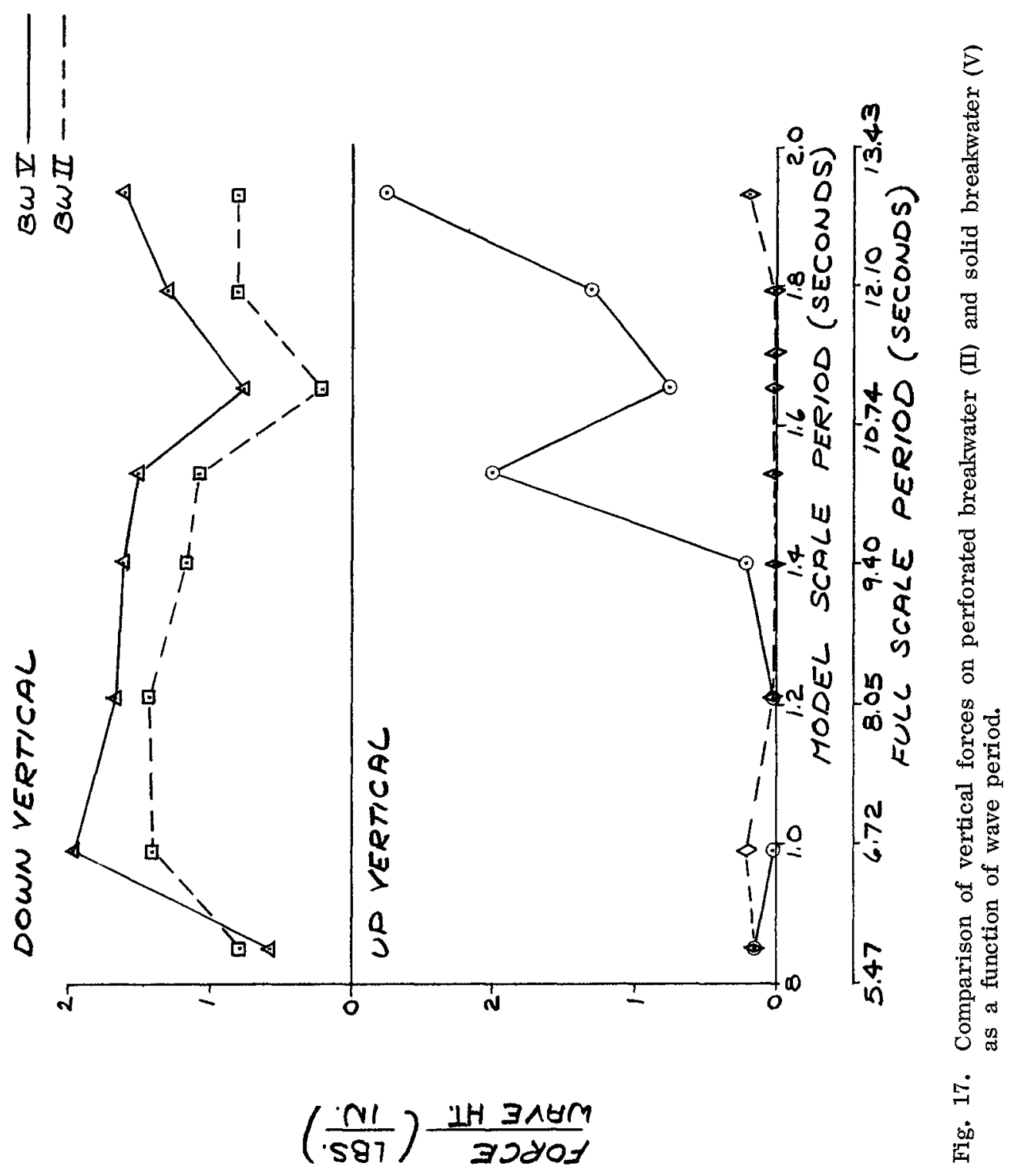




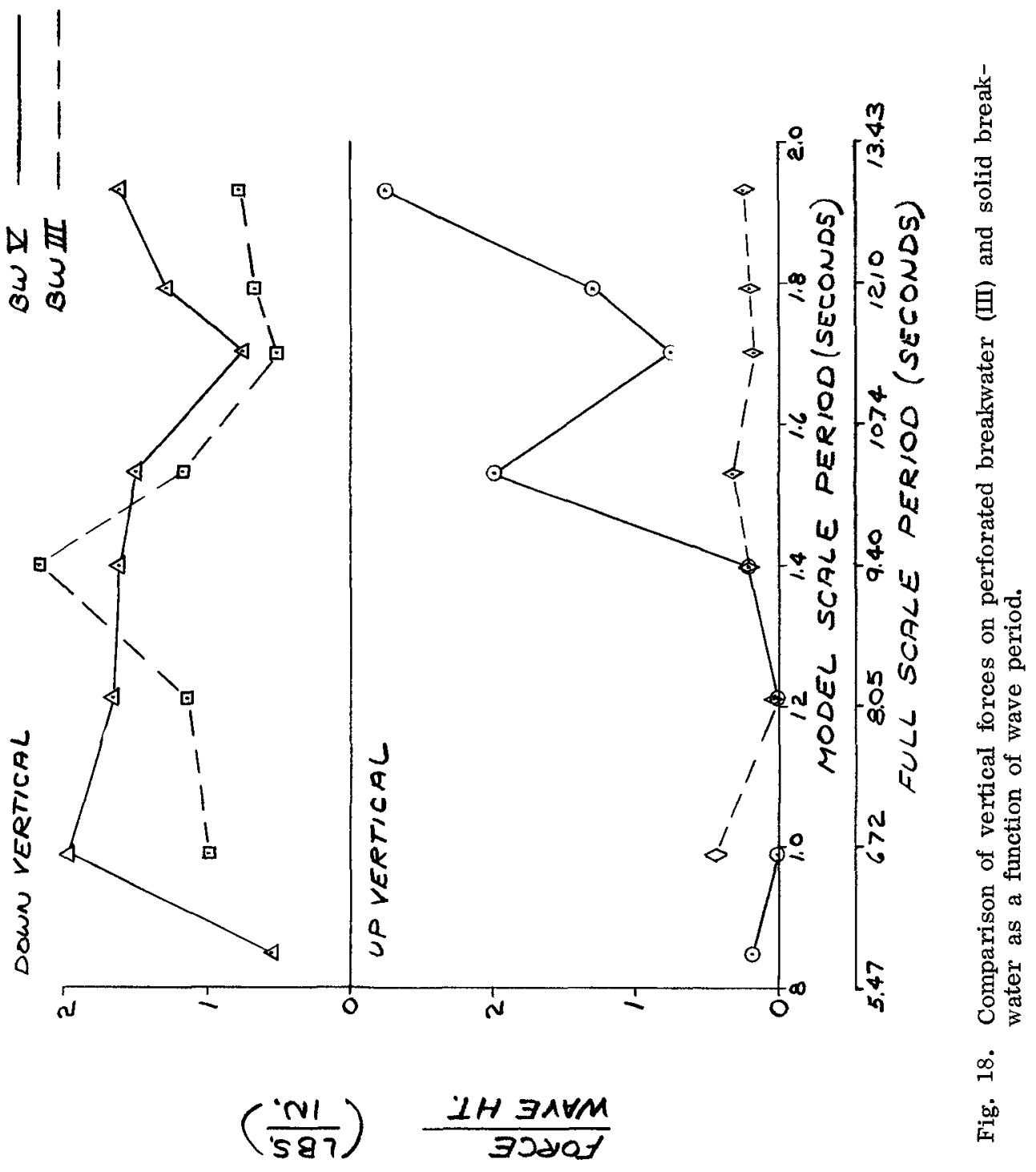




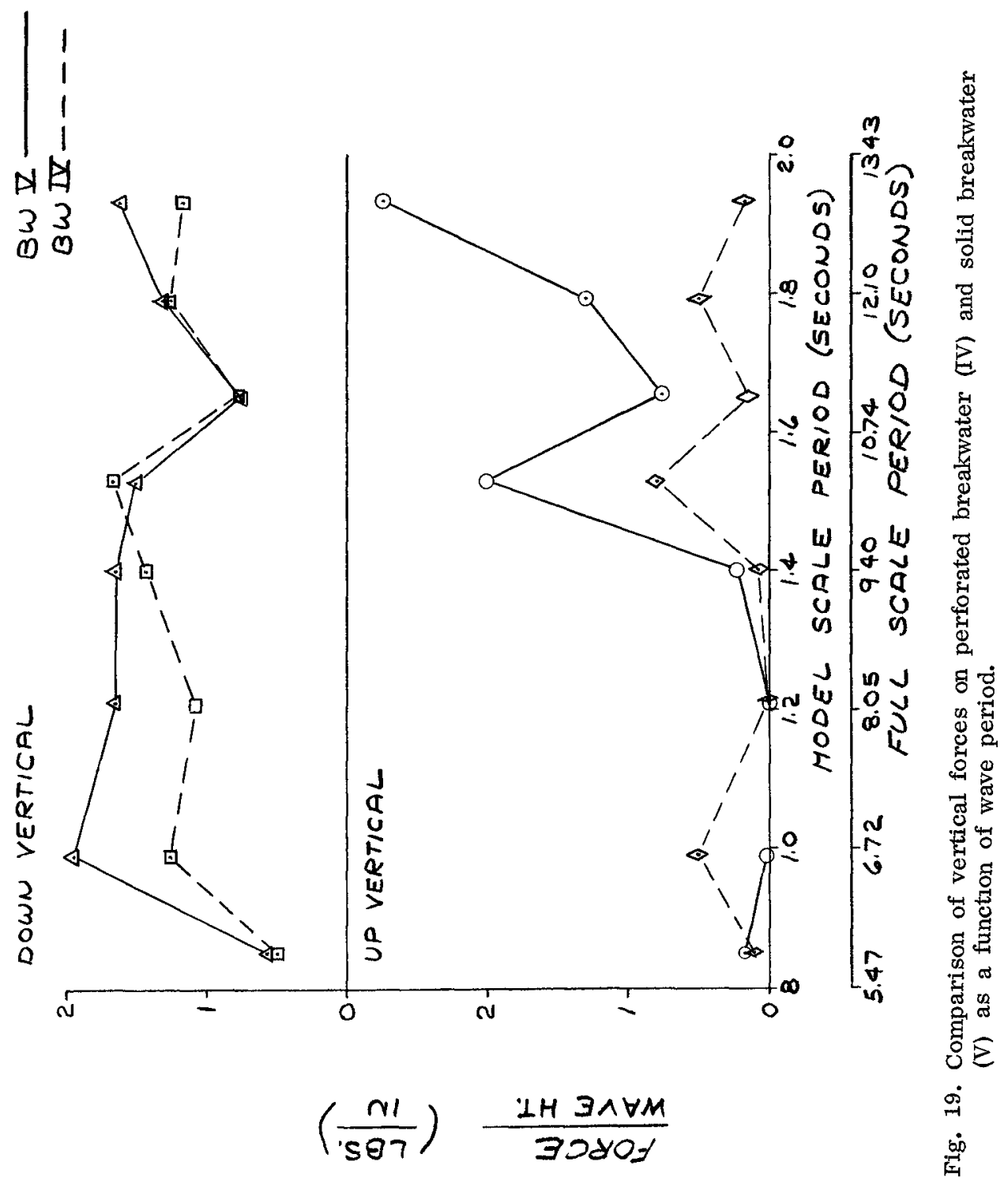




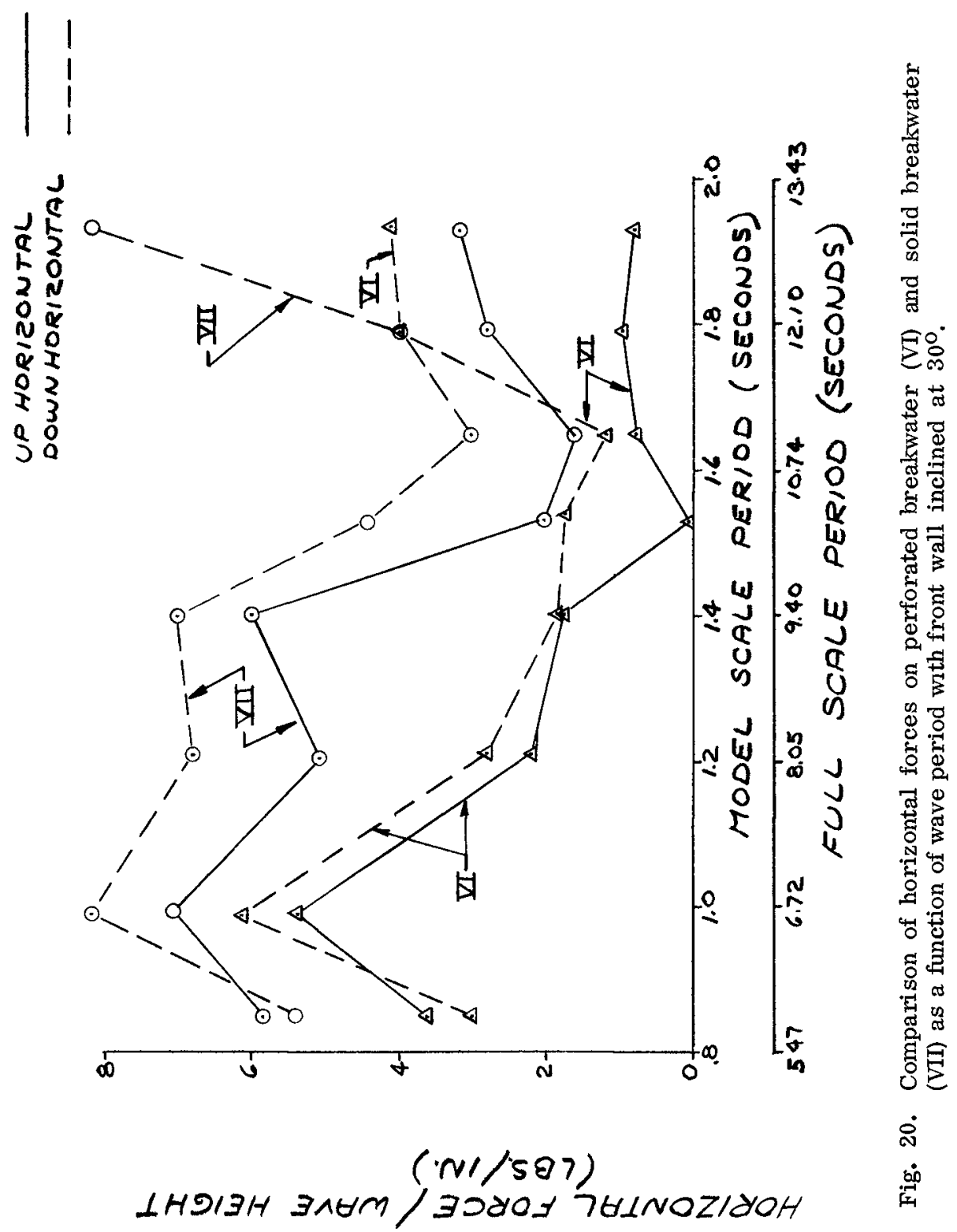




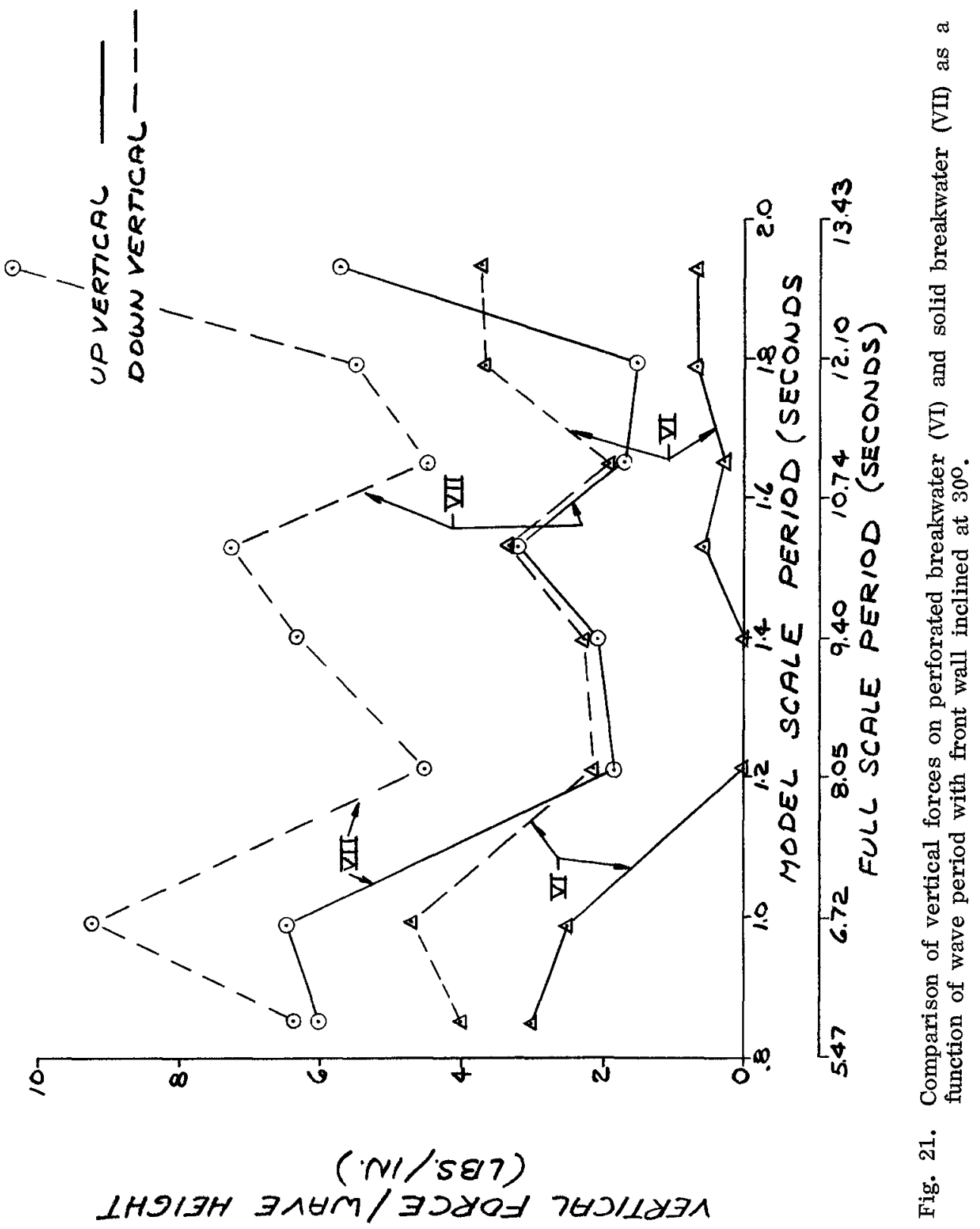


PERFORATED PORTABLE BREAKWATER

1119

SEAWARD MOORING LINE

SOLID BTW. PERFORATED B.W. $A-\triangle$
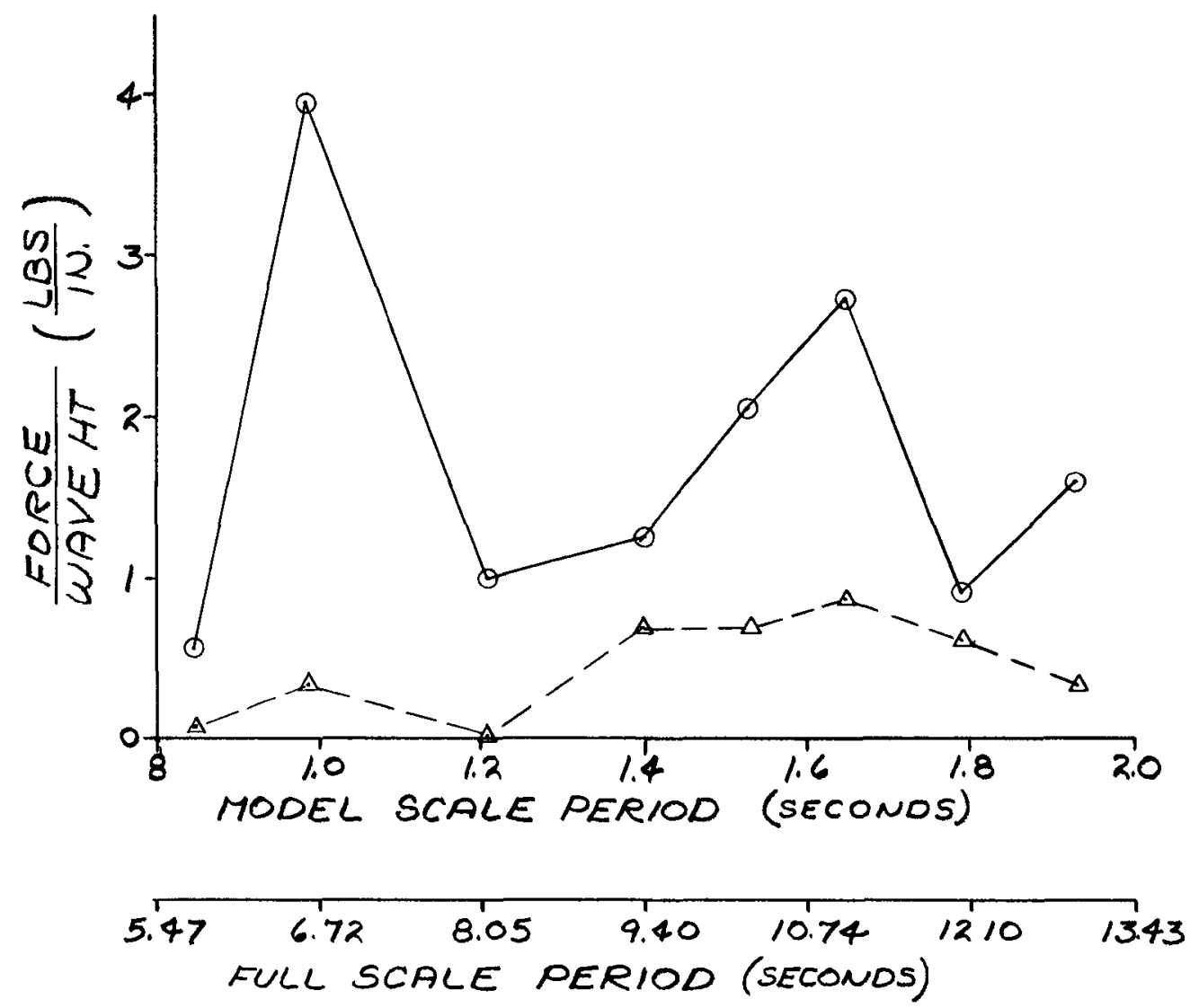

Fig. 22. Forces on seaward mooring line (port side). 


\section{SEAWARD MOORING LINE}

SOLID B.W. O-

PERFORATED BW. $\triangle--\triangle$

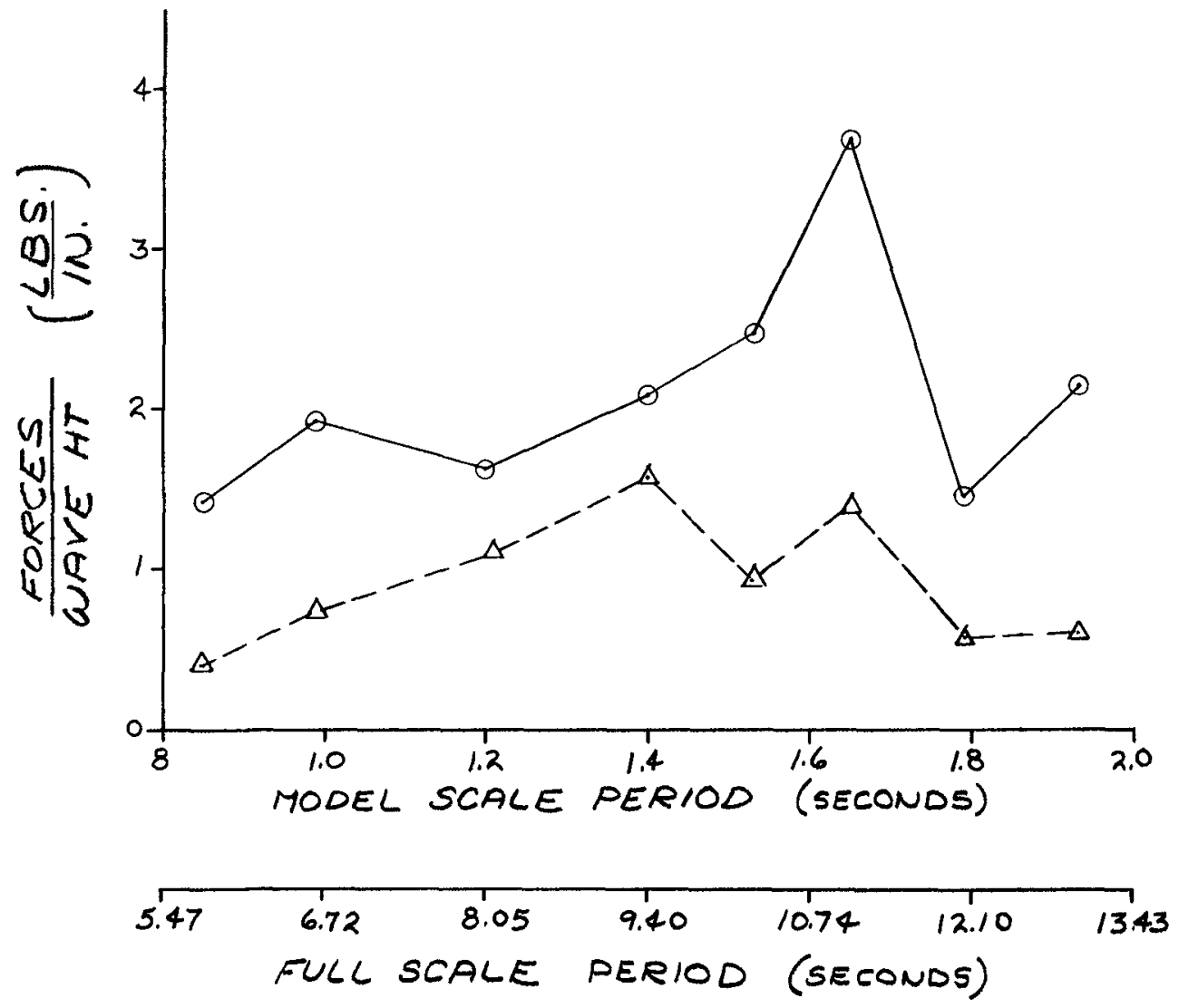

Fig. 23. Forces on seaward mooring line (starboard side). 
SHOREWARD MOORING LINE

SOLID B.W. O- O

PERFORATED B.W. $\triangle \cdots$

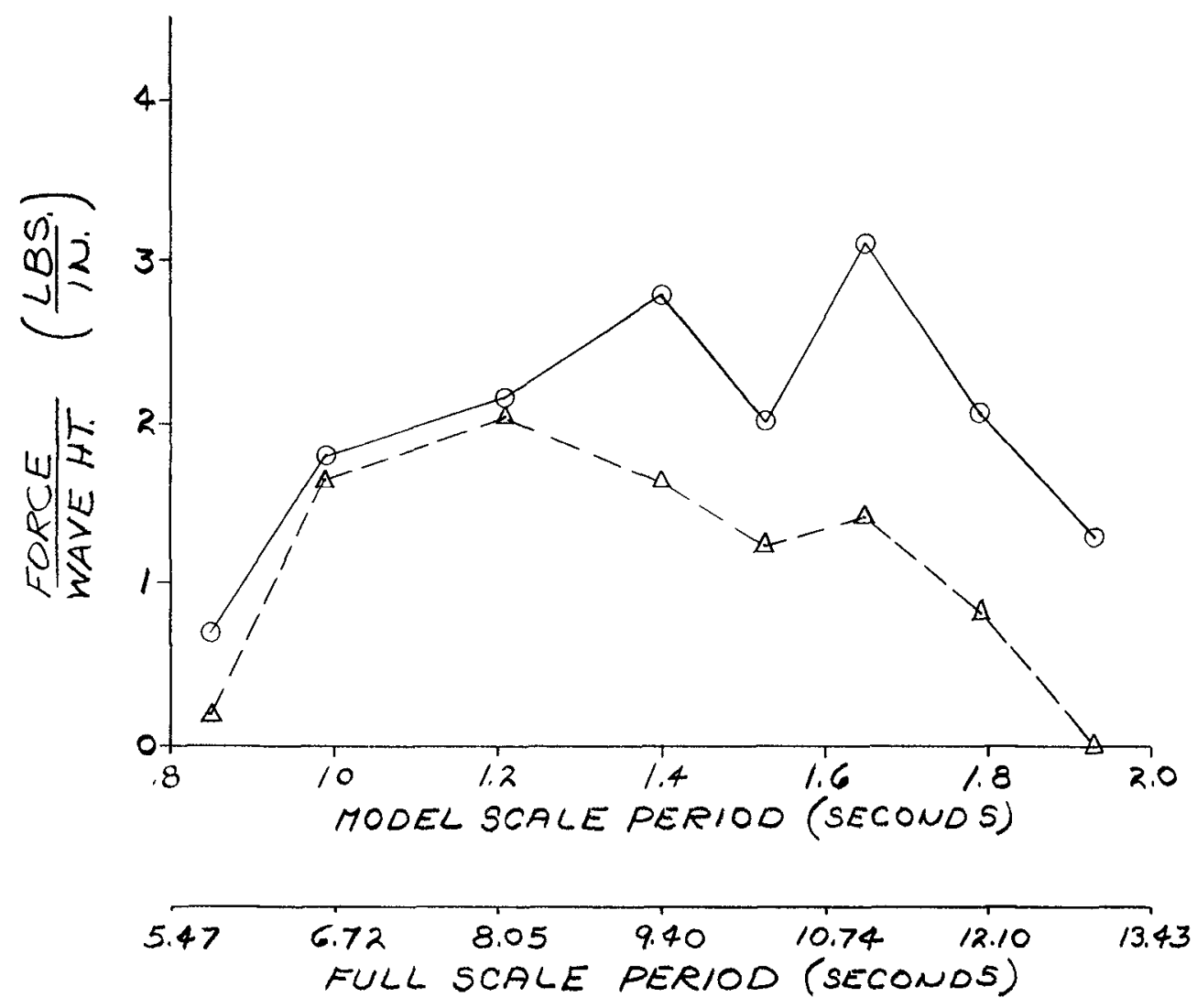

Fig. 24. Forces on shoreward mooring line (port side). 
1122

COASTAL ENGINEERING

SHOREWARD MOORING LINE

SOLID BMW.

PERFORATED B.W. $\triangle-\ldots-$

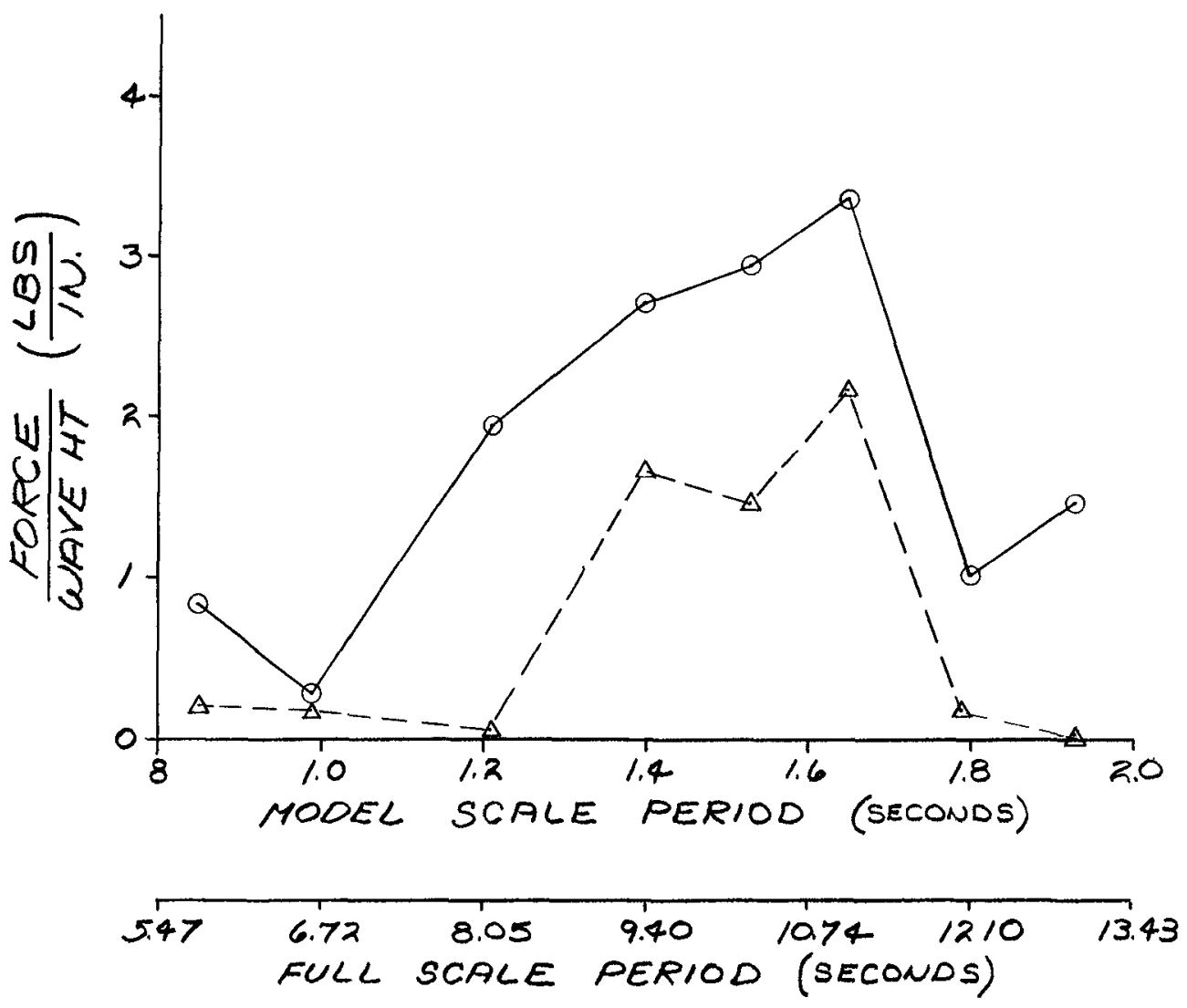

Fig. 25. Forces on shoreward mooring line (starboard side). 


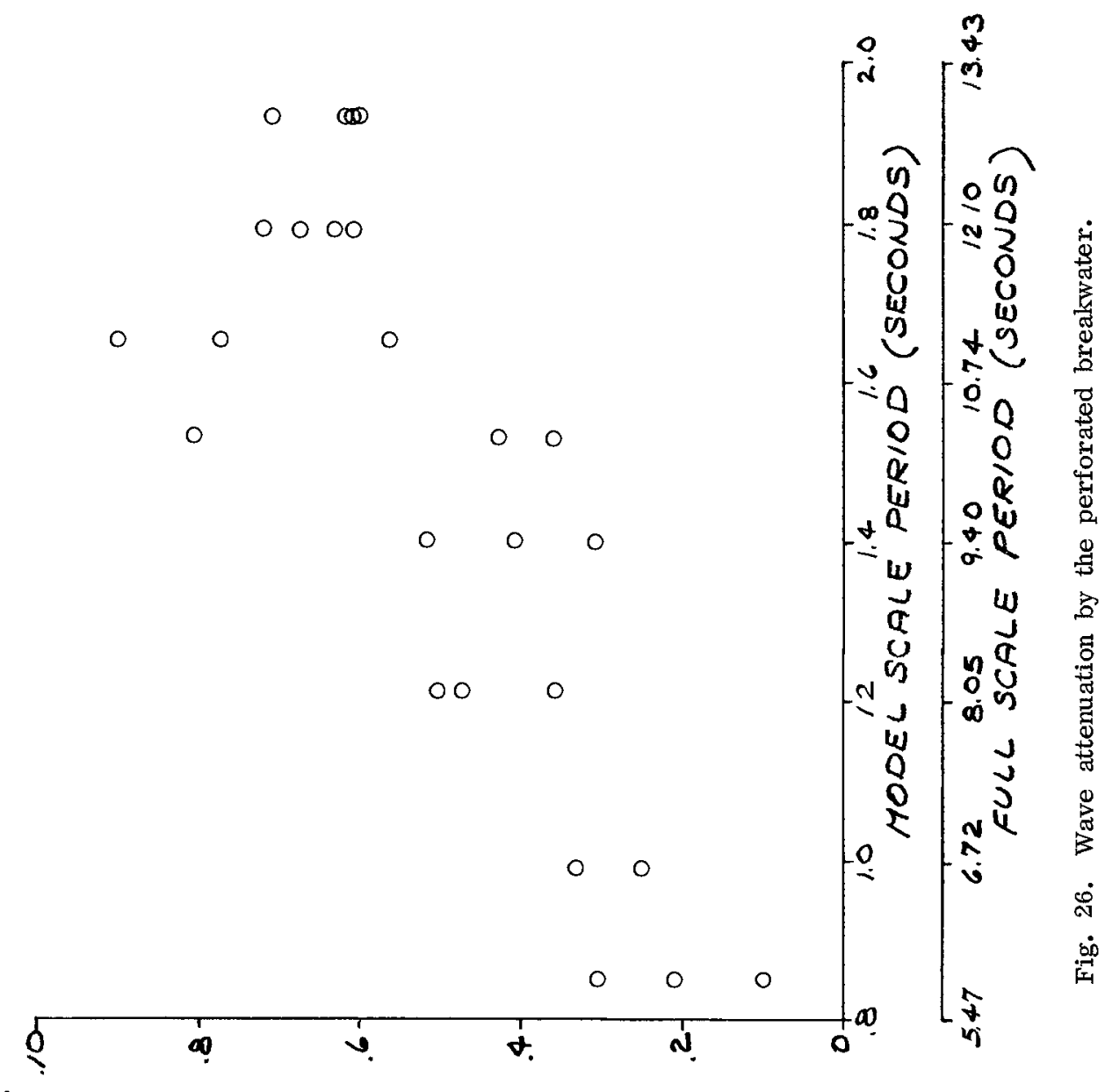

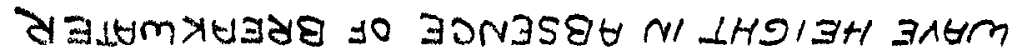

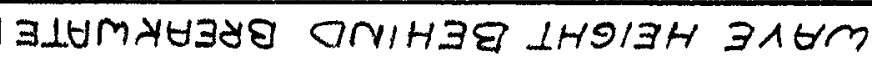




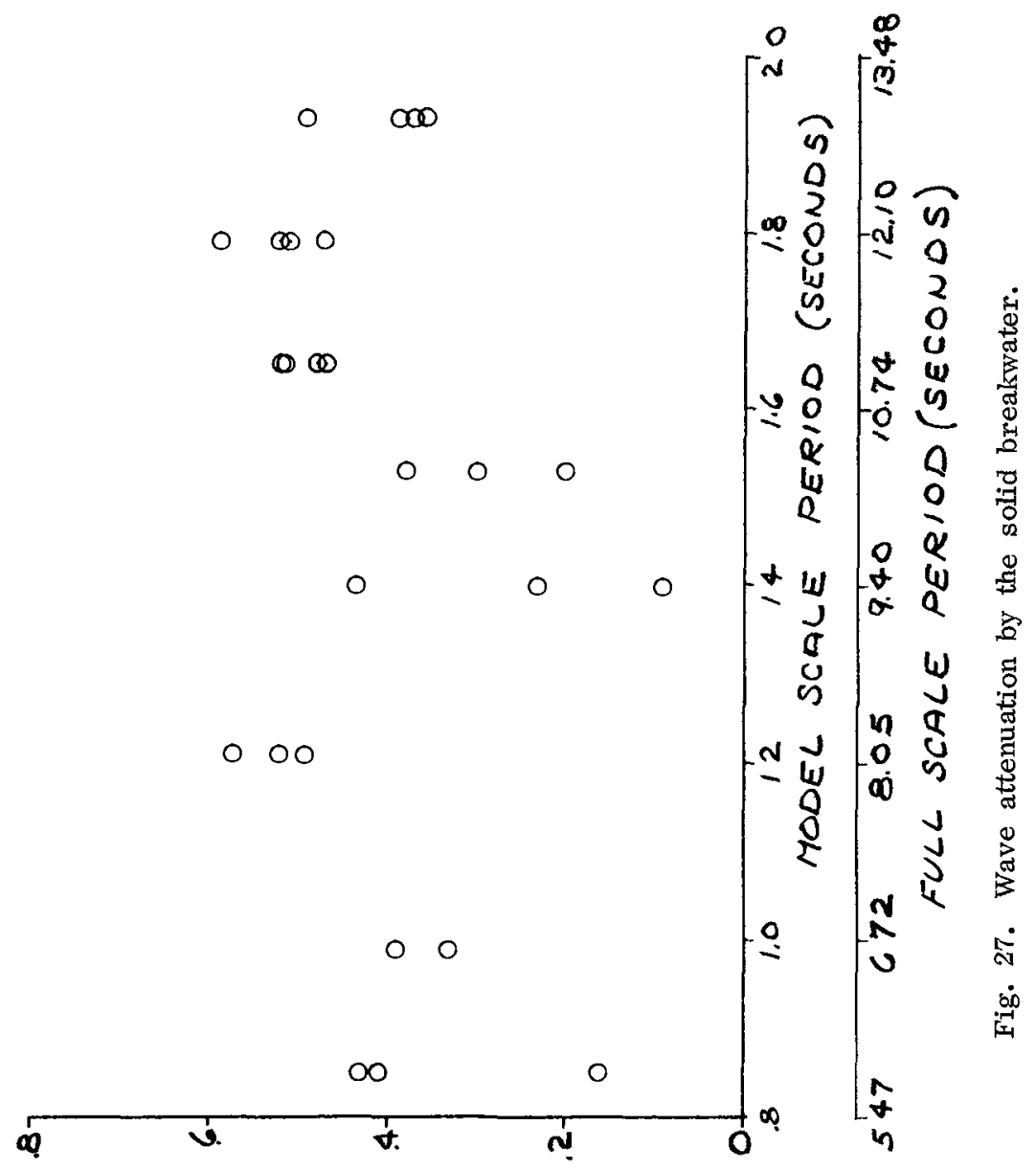

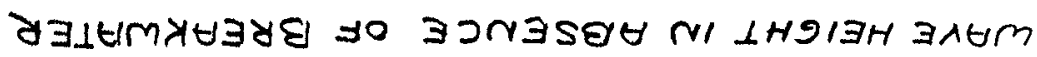

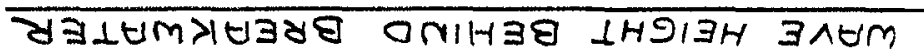




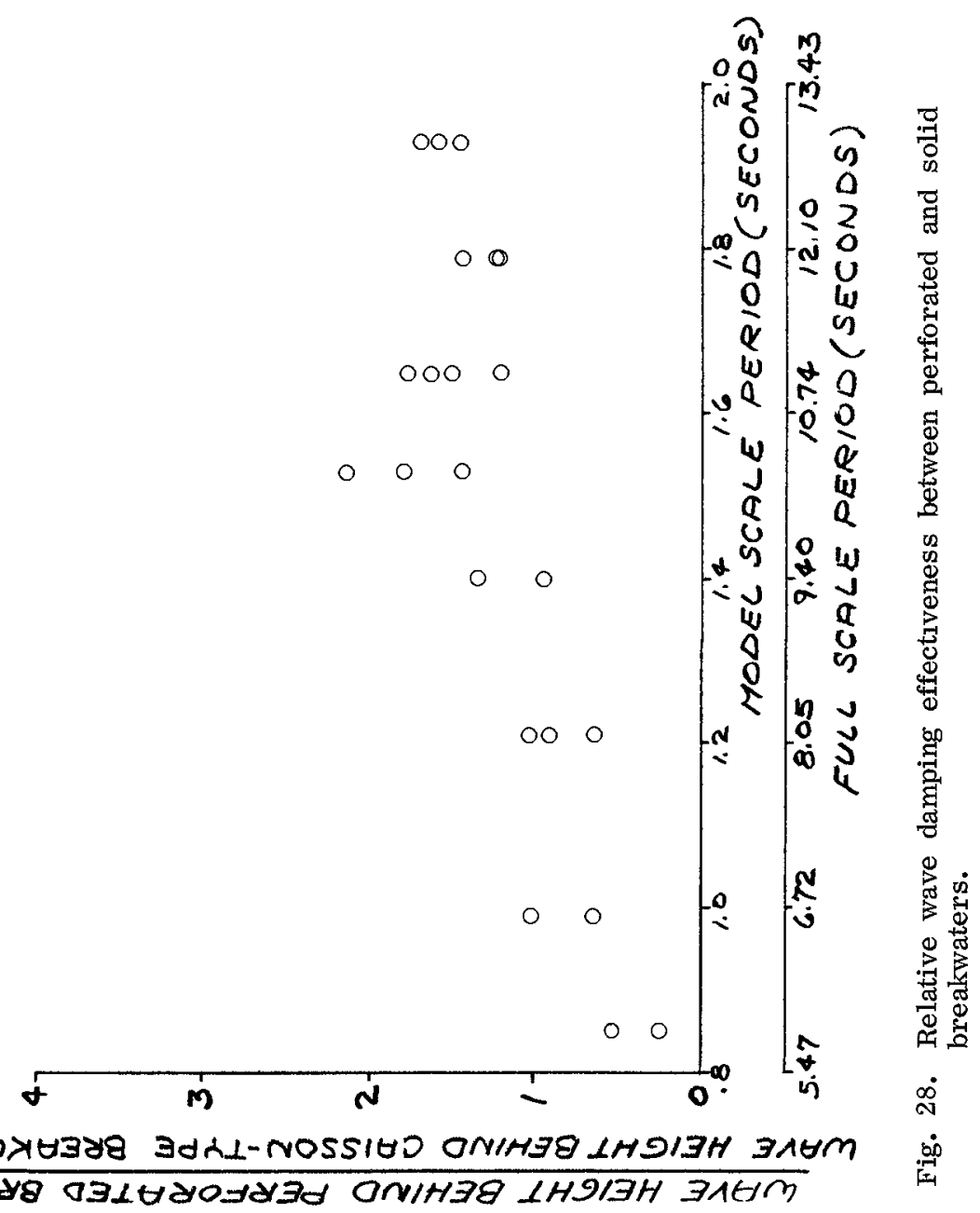



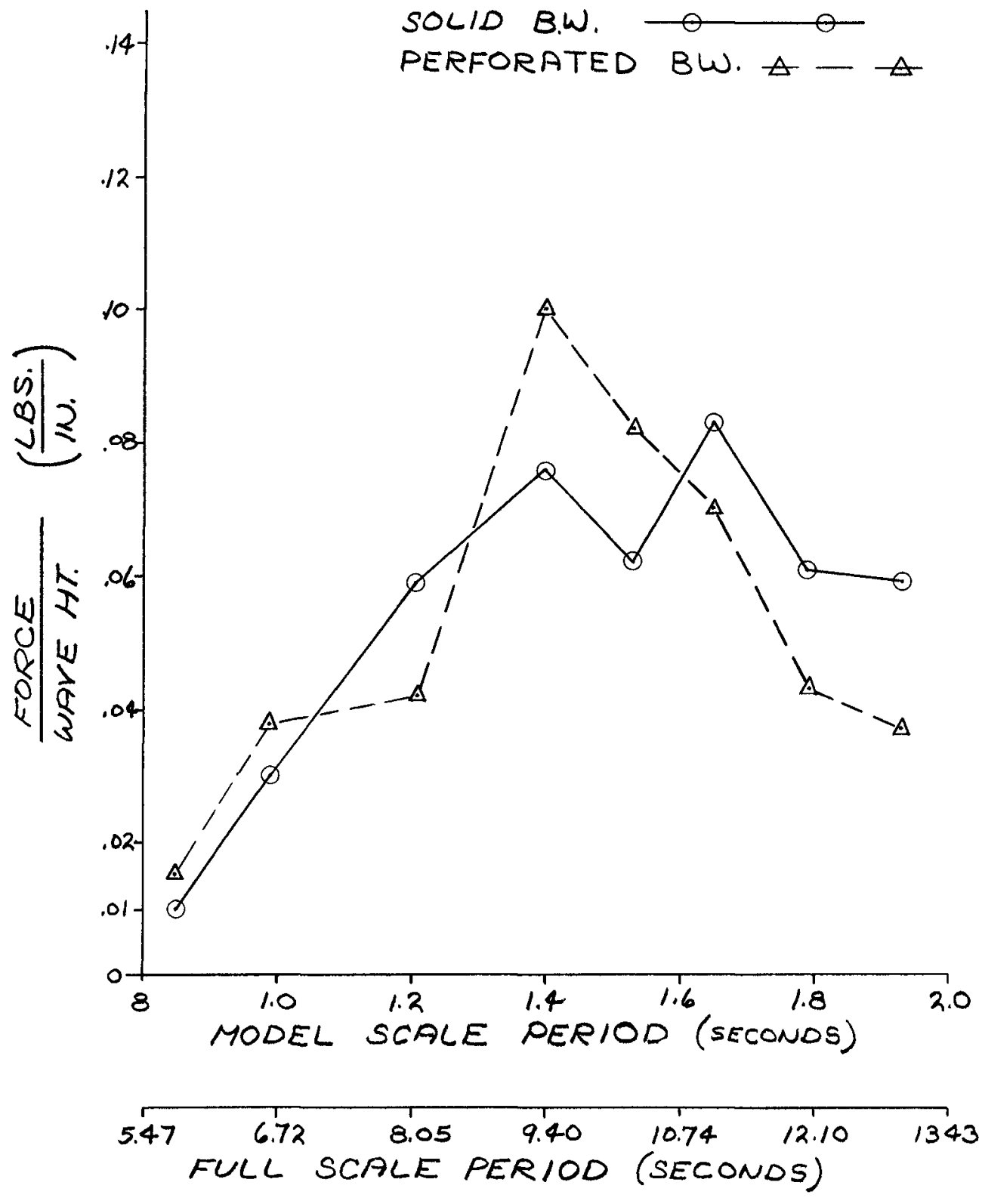

Fig. 29. Comparison of horizontal acceleration of breakwater models. 

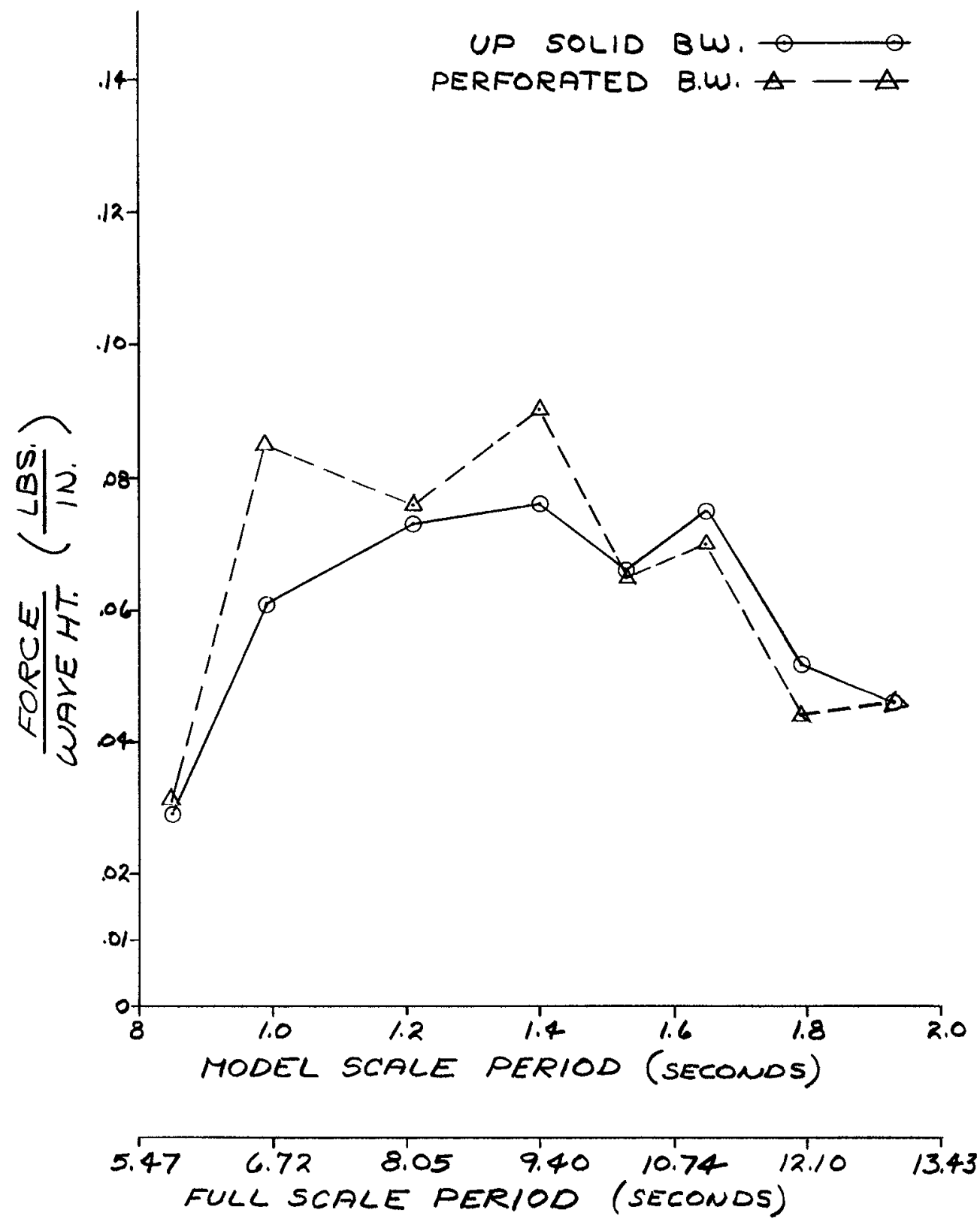

Fig. 30. Comparison of vertical acceleration (upward) of breakwater models. 


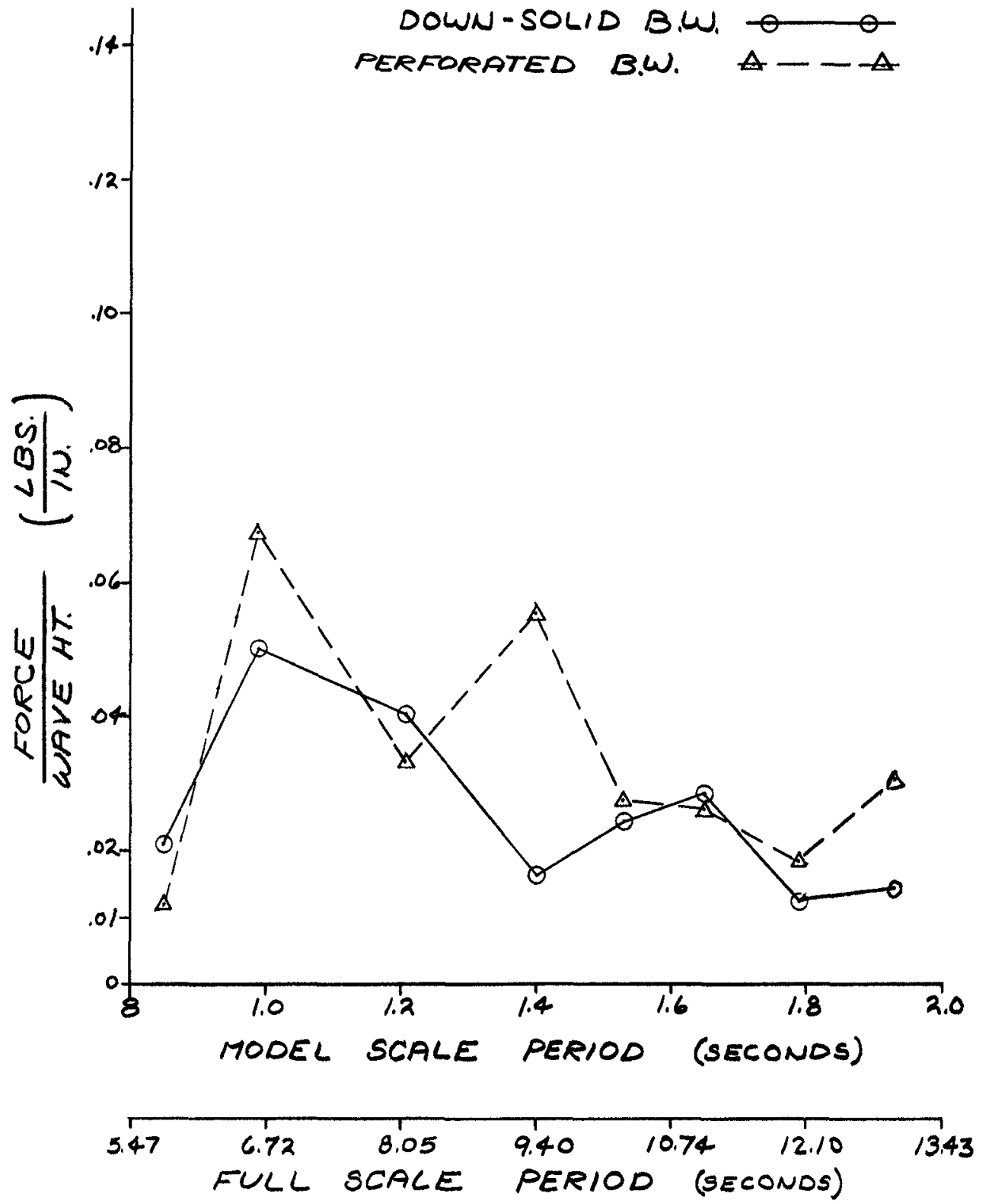

Fig. 31. Comparison of vertical acceleration (down) of breakwater models. 

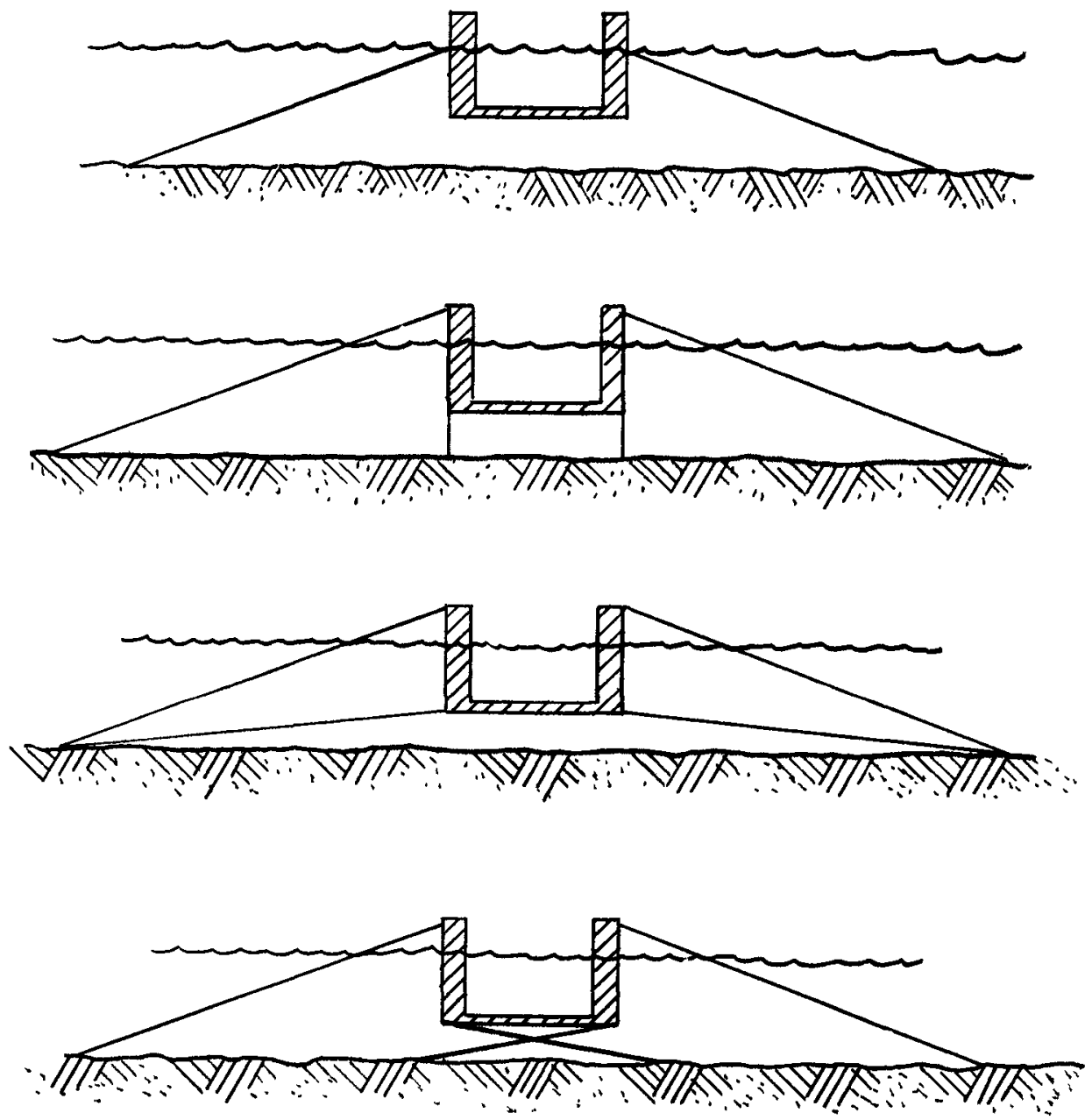

Fig. 32. Suggested mooring systems for roll reduction. 